(2) Open Access Full Text Article

\title{
Investigation of I, 3, 4 Oxadiazole Derivative in PTZ-Induced Neurodegeneration: A Simulation and Molecular Approach
}

\author{
Muhammad Faheem (1D) \\ Yusuf S Althobaiti ${ }^{2,3}$ \\ Abdul Waheed Khan ${ }^{4}$ \\ Aman Ullah (ID) \\ Syed Hussain Ali $\mathbb{D}^{\prime}$ \\ Umair llyas'
}

'Riphah Institute of Pharmaceutical Sciences, Riphah International University, Islamabad, Pakistan; ${ }^{2}$ Department of Pharmacology and Toxicology, College of Pharmacy, Taif University, Taif, 21944, Saudi Arabia; ${ }^{3}$ Addiction and

Neuroscience Research Unit, Taif University, Taif, 21944, Saudi Arabia; ${ }^{4}$ Department of Pharmacy, The University of Lahore, Islamabad, Pakistan
Correspondence: Muhammad Faheem; Yusuf S Althobaiti

Email muhammad.faheem@riphah.edu.pk; althobaiti@tu.edu.sa
Objective: The study investigated the effect 5-[(naphthalen-2-yloxy) methyl]-1,3,4-oxadiaszole2-thiol (B3) in animal model of acute epileptic shock.

Methods: The pharmacokinetics profile of B3 was checked through SwissADME software. The binding affinities of B3, diazepam, and flumazenil (FLZ) were obtained through Auto Dock and PyRx. Post docking analysis and interpretation of hydrogen bonds were performed through Discovery Studio Visualizer 2016. Molecular dynamics simulations of three complexes were carried out through Desmond software package. B3 was then proceeded in PTZinduced acute seizures models. Flumazenil was used in animal studies for elucidation of possible mechanism of B3. After behavioral studies, the animals were sacrificed, and the brain samples were isolated and stored in $4 \%$ formalin for molecular investigations including $\mathrm{H}$ and $\mathrm{E}$ staining, IHC staining and Elisa etc.

Results: The results demonstrate that B3 at 20 and $40 \mathrm{mg} / \mathrm{kg}$ prolonged the onset time of generalized seizures. B3 considerably increased the expression of protective glutathione S-transferase and glutathione reductase and reduced lipid peroxidation and inducible nitric oxide synthase $(\mathrm{P}<0.001)$ in the cortex. B3 significantly suppressed $(\mathrm{P}<0.01)$ the over expression of the inflammatory mediator tumor necrosis factor- $\alpha$, whose up-regulation is reported in acute epileptic shocks.

Conclusion: Hence, it is concluded from the aforementioned results that B3 provides neuroprotective effects PTZ-induced acute epileptic model. FLZ pretreatment resulted in inhibition of the anticonvulsant effect of B3. B3 possesses anticonvulsant effect which may be mediated through $\mathrm{GABA}_{\mathrm{A}}$ mediated antiepileptic pathway.

Keywords: docking, molecular dynamic simulations, gamma amino butyric acid A

\section{Introduction}

Epilepsy is serious, heterogeneous neurological condition that negatively affects the quality of life and standard of living in human populations. Seizures are electrical discharges in the brain resulting from either too much excitation or too little inhibition specifically in cortical region of brain. The excitation and inhibition of neurons may be mediated by many distinctive neurotransmitters. ${ }^{1}$ Glutamate is implicated in the pathophysiology of epilepsy has already been identified. ${ }^{2}$ It directly affects over 4 lac people in the UK and up to 60 million people

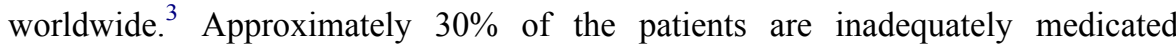
owing to tolerance and aggressive regimen. Most epileptic patient have behavioral comorbidities, including depression, anxiety, psychosis, and impaired cognitive 
performance. The risk factors of epilepsy include intracranial bleeding or stroke, tumors, central nervous system infections, prolonged febrile seizures, and other occurrences of status epilepticus. ${ }^{4}$

In addition to glutamate, which is excitatory in nature, an inhibitory neurotransmitter termed as gamma amino butyric acid $\mathrm{A}\left(\mathrm{GABA}_{\mathrm{A}}\right)$ is available in the cortex to prevent or balance the over stimulation caused by excitatory neurotransmitter. ${ }^{5}$ Currently, benzodiazepines are considered for the management of seizures by increasing the chloride conductance and causing hyper polarization mean while reducing hyper excitability and minimizing seizures attacks. $^{6}$

Since chronic use of benzodiazepines is associated with dependence and tolerance, it is decided to conduct a study based on the pharmacological investigation of the synthetic compound 1,3,4- oxadiazole derivative (B3) in phenyltetrazole (PTZ) induced acute and chronic seizures. PTZ, a benzodiazepine receptor antagonist, widely used animal model in drug discovery and development process. Its single high dose intraperitoneal injection develops acute convulsion while sequential medium doses produce kindling seizures. ${ }^{7}$ Another antidote of benzodiazepine (BDZ) receptor is flumazenil that is also used for reversing the BDZ overdose. ${ }^{8,9}$ As PTZ in involved in causing neuroinflammation so the selected compound for the study must have a potential antiinflammatory nature in order to cope up with PTZ-induced acute epileptic shock. In this context the selected compound has been already reported for antioxidant, analgesic, anti-inflammatory, toxicity assessment, tumor inhibition activities and also effective in relieving chronic constriction induced painful symptoms. ${ }^{10,11}$ The two-dimensional (2D) and three-dimensional (3D) structures of B3 are shown in Figures 1A and 2A, respectively. This study utilized the computational techniques, behavioral approach, and molecular investigation to elucidate the ameliorative effect of B3 in PTZ-induced seizures.

\section{Materials and Methods}

\section{Materials}

Proteinase $\mathrm{K}$ and PBS tablets were ordered from MPBiomedicals, USA. N-(1-Naphthyl) ethylenediamine dihydrochloride, trichloroacetic acid (TCA), 5,5'-dithiobis(2-nitro benzoic acid) (DTNB), 1-chlor-2,4-dinitrobenzene (CDNB) and reduced glutathione (GSH) were obtained from Sigma Aldrich, USA. Mouse monoclonal anti-TNF- $\alpha$ (SC52B83722), The 3,3'-Diaminobenzidine (DAB, SC-216567)

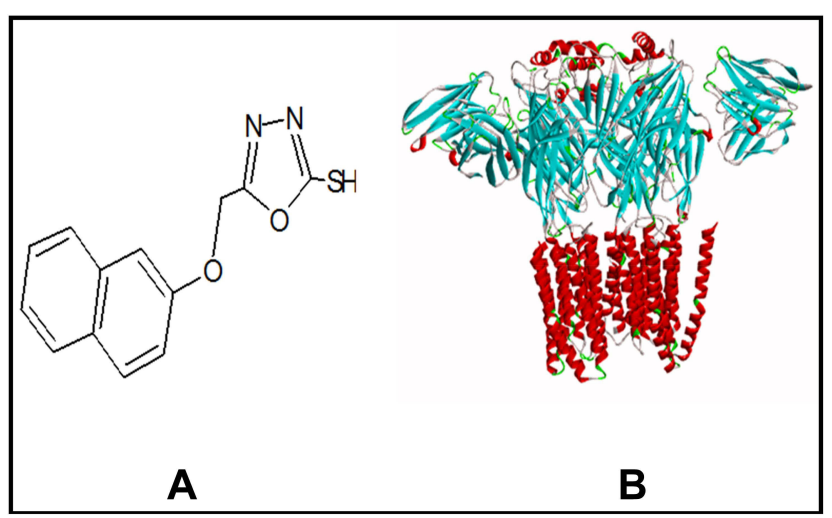

Figure I (A) represents structure of 5-[(naphthalen-2-yloxy)methyl]-1,3,4-oxadiazole-2thiol (B3) and (B) the target protein gamma amino butyric acid (GABA) with protein data band $($ PDB I.D $=6 \mathrm{D} 6 \mathrm{~T})$.

and Avidin-biotin complex (ABC kit, SC-516216) were acquired from Santa-Cruz Biotechnology, USA. Mounting media (ab-10431) and horseradish peroxidase-conjugated secondary antibodies (ab-6789, ab-6721) were acquired from Abcam, UK. Flumazenil (FLZ) and diazepam (DZM) was procured from Shifa International Hospital, Islamabad, Pakistan. Phenyltetrazole (PTZ) was obtained from Sigma Aldrich, USA. TNF- $\alpha$ enzyme linked immunosorbent assay (ELISA) kit (Cat \# SU-B3098) was bought from ShanghaiYuchun Biotechnology, China. The compound 1, 3, 4-oxadiazole derivative (B3) was obtained as gift from pharmaceutical chemistry post graduate lab, Riphah International University, Islamabad, Pakistan.

\section{Animals}

In this research, Swiss albino mice of weight $25-30 \mathrm{~g}$ were used. Mice were allowed to have free access to water and diet ad libitum with 12 hours supply of each light and dark and housed in standard environment of humidity and temperature $\left(25-30^{\circ} \mathrm{C}\right)$. The research study was conducted according to guidelines set by ethical committee of Riphah Institute of Pharmaceutical Sciences, Riphah International University, Islamabad (REC/RIPS/2021/01).

\section{Animal Grouping and Dosing}

Mice were distributed into following groups (each having 6 rats).

Investigation of Anticonvulsant Effect of $B 3$ PTZ + NS: Group I served as sham (saline $10 \mathrm{~mL} / \mathrm{Kg}$ ) + PTZ $(90 \mathrm{mg} / \mathrm{Kg})$

PTZ + B3: Group II was administered withB3 (20 mg/ $\mathrm{Kg}$ ) and $\mathrm{PTZ}$ 


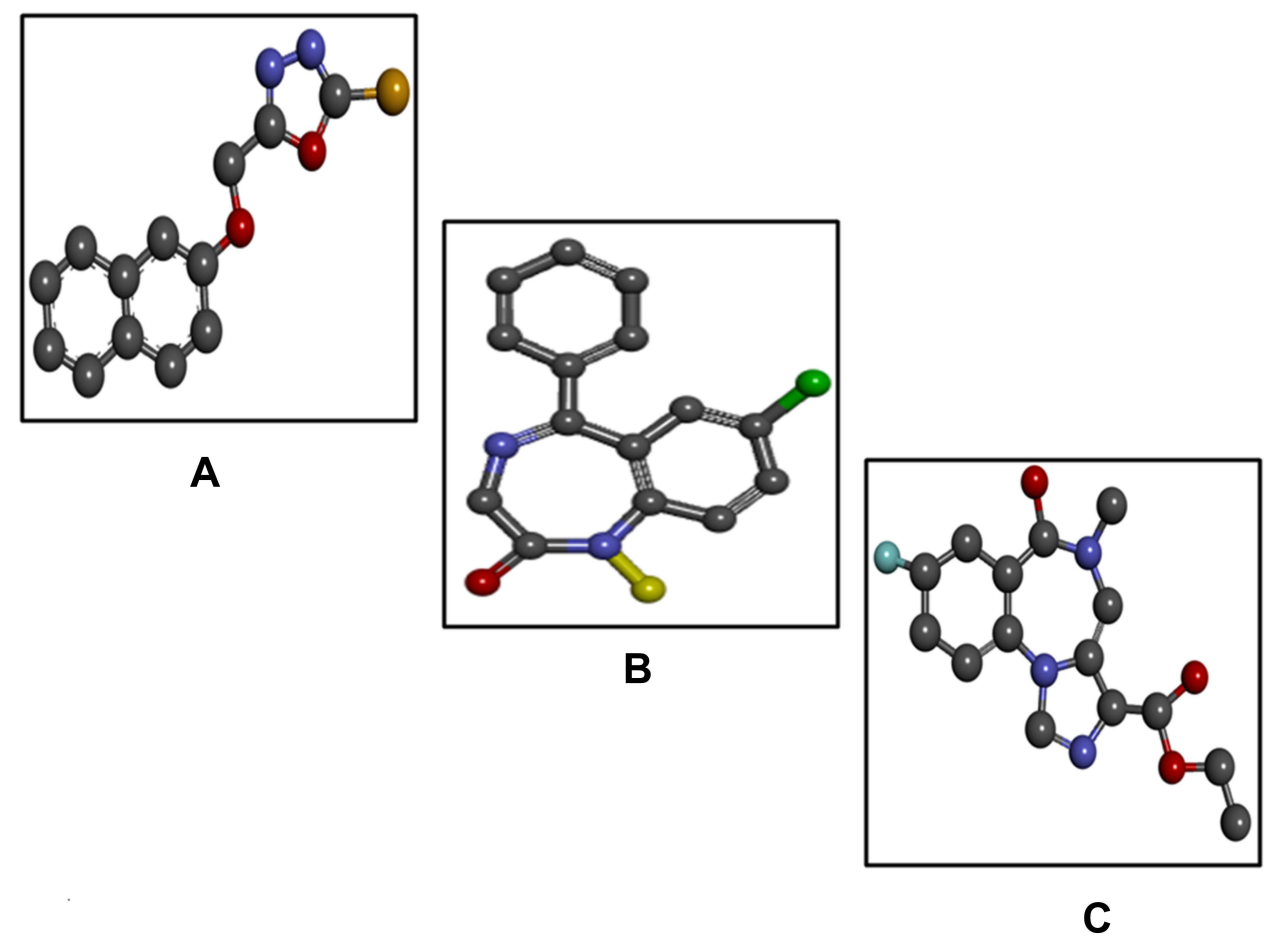

Figure 2 (A-C) represent the three-dimensional structure of ligands 5-[(naphthalen-2-yloxy) methyl]-1,3,4-oxadiaszole2-thiol (B3), diazepam (DZM), and flumazenil (FLZ), respectively drawn using Discovery Studio Visualizer 2016.

PTZ + B3: Group III was administered with B3 $(40 \mathrm{mg} / \mathrm{Kg})$ and PTZ

PTZ + DZM: Group IV served standard group administered with PTZ + DZM $(1 \mathrm{mg} / \mathrm{Kg})$

\section{Investigation of Flumazenil Inhibitory} Effect on Anticonvulsant Effect of B3

PTZ + NS: Group I served as sham (saline $10 \mathrm{~mL} / \mathrm{Kg})+$ PTZ $(90 \mathrm{mg} / \mathrm{Kg}$ )

PTZ + DZM: Group II was administered with DZM $(1 \mathrm{mg} / \mathrm{Kg})+$ PTZ.

PTZ + FLZ: Group III served inhibitor group administered with FLZ $(2 \mathrm{mg} / \mathrm{Kg})+$ PTZ

PTZ + B3: Group IV was administered with B3 $(40 \mathrm{mg} / \mathrm{Kg})$ and PTZ

PTZ + B3+ FLZ: Group V was administered with B3 $(40 \mathrm{mg} / \mathrm{Kg})+$ FLZ $(2 \mathrm{mg} / \mathrm{Kg})$ and DZM

PTZ+ DZM+ FLZ: Group VI was administered with B3 $(30 \mathrm{mg} / \mathrm{Kg})+$ FLZ $(2 \mathrm{mg} / \mathrm{Kg})$ and DZM

\section{In-Silico Investigation}

\section{Preparation of Ligand}

Ligand 1, 3, 4 oxadiazole as shown in Figure 1A was prepared through ChemSketch and then converted to
3D structure through Discovery Studio Visualizer 2016 (DSV 2016) and saved in PDB (protein data band) format ${ }^{12}$ as presented in Figure 2A. The structure of diazepam and flumazenil was retrieved from PubChem structure search in mol format, converted to PDB format through Open Bebel and saved in PDB format through DSV 2016 as given in Figure $2 \mathrm{~B}$ and $\mathrm{C}$.

\section{Preparation of Target}

Target protein gamma amino butyric acid $\mathrm{A}\left(\mathrm{GABA}_{\mathrm{A}}\right)$ with PDB ID: 6D6T was retrieved from protein data bank and purified through DSV 2016 for further processing as shown in Figure 1B.

\section{Identification of Active Pockets}

The active pockets of the target protein as shown in Figure 3 were identified through Dog site scorer, an online tool for active site retrieval. ${ }^{13}$ Dog site scorer is capable of giving volume, surface area, drug score, simple score of active pockets. The first pocket is considered the most important site for checking a ligand to whether drug able or not. Some important description of targets protein is shown in Table $1 \mathrm{~A}-\mathrm{F}$. 


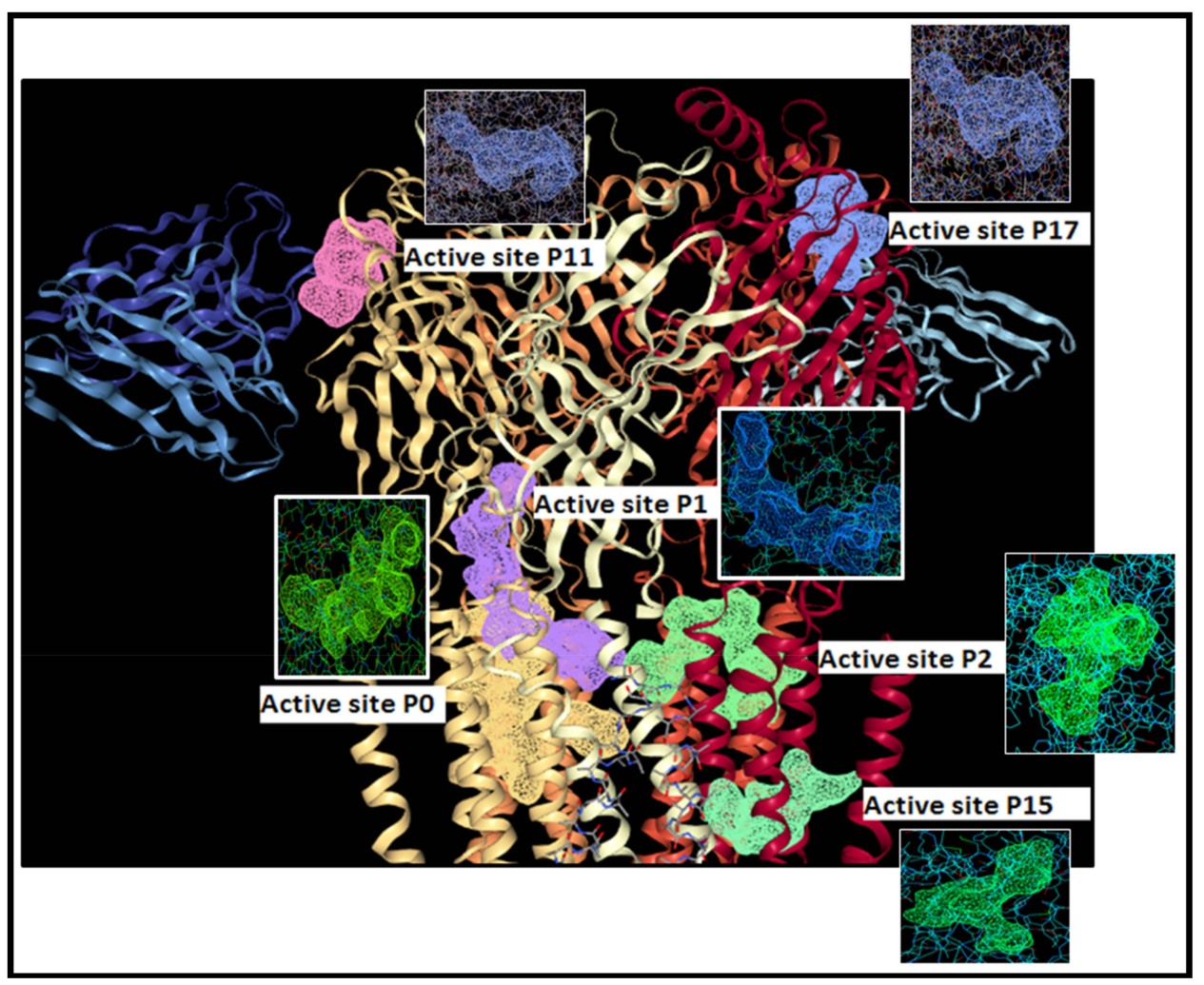

Figure 3 The active sites of gamma amino butyric acid (GABA) (PO, PI, P2, PII, PI5 and pI7) obtained through Dog site scorer.

\section{Grid Box Selection}

After selecting the active site, the important step is selection of Grid box using PyRx software. The Grid centers of the Grid box were $\mathrm{X}=133.02, \mathrm{Y}=147.50$ and $\mathrm{Z}=133.19$, and $\mathrm{X}=50, \mathrm{Y}=50$, and $\mathrm{Z}=50$. The dimensions in Angstrom were $\mathrm{X}=98.17, \mathrm{Y}=121.63$ and $\mathrm{Z}=100.16$ and the spacing angstrom was 0.375 . The Grid box was set in such a way that all the protein was covered inside the Grid box.

\section{Swiss ADME}

SwissADME is an online technique to check various parameters including pharmacokinetic properties, drug likeliness, physicochemical properties, lipophilicity and medicinal chemistry ligand before processing the drug to animal model.

\section{Docking}

Auto dock vina and PyRx were used for docking of ligand against target. Both the ligand and target were first converted to PDBQT through AutoDock and then loaded in PyRx. The docking was carried out by selecting the amino acid of the active site of the target protein. After running of ligand receptors complex through PyRx binding energies were obtained which are expressed in $\mathrm{kcal} / \mathrm{mol}$. The best pose obtained through PyRx was then Proceeded for post docking analysis was performed through DSV 2016 for schematic representation of hydrogen bonds (classical and non-classical), hydrophobic interactions and amino acid residues involved in hydrogen bonding of best docked pose of ligand protein complex. ${ }^{14}$

\section{Molecular Dynamics Simulation}

After molecular docking studies molecular dynamics simulations study of three complexes B3-GABA, DZMGABA and FLZ-GABA were carried out using Desmond software package to tracked molecular interaction. ${ }^{16}$ In MD simulation the complexes were immersed in an autocalculated orthorhombic box which was added with 68444, 68446 and 68441 for complexes B3-GABA, DZM-GABA and FLZ-GABA respectively using simple point charge water model. The optimization of the model is further done with optimized potential for liquid simulations (OPLS5). The complexes of the system were neutralized and the system was made isotonic with the addition $\mathrm{NaCl}$ $(\mathrm{Na}=50.73$ and $\mathrm{Cl}=60.30 \mathrm{mM})$. In order to make the 
Table I The Dog Site Scorer Value of the Target Protein Gamma Amino Butyric Acid a (GABAa) with Protein Data Band (PDB) ID: 6D6T. IA Represents the First 3 Pockets P_0, P_I and P_2 and Then Randomly Selected Three Pockets for Docking P_II, P_15 and P_I7. IB Represents the Size and Shape of Each Pocket (P_0, P_I and P_2, P_II, P_I5) with Respects to Its Volume, Surface Area, Depth, Ellipsoid Main Axis Ratio c/a, Ellipsoid Main Axis Ratio b/a, and Enclosure. IC Represents the Elements of Each Pocket Including Pocket Atom, Carbon, Nitrogen, Oxygen, and Sulfur. ID Represents the Functional Group of Each Pocket Involve in Bonding as Hydrogen Bond Donor, Acceptors, Metal, Hydrophobic Interactions, and Hydrophobicity Ratio. IE Represents the Amino Acid Composition of Each Pocket Involved in Bonding as Apolar Amino Acid Ratio, Polar Amino Acid Ratio, Positive Amino Acid Ratio, and Negative Amino Acid Ratio. IF Represents a Specific Amino Acid in a Given Pocket of the Target Involve in Bonding as Polar Amino Acid Ratio, Polar Amino Acid Ratio, Positive Amino Acid Ratio, and Negative Amino Acid Ratio

\begin{tabular}{|c|c|c|c|c|c|c|c|}
\hline \multicolumn{8}{|l|}{ IA } \\
\hline Name & & Volume & Surface area & \multicolumn{2}{|c|}{ Drug score } & \multicolumn{2}{|c|}{ Simple score } \\
\hline P_0 & & 1205.76 & $|55| .7 \mid$ & \multicolumn{2}{|c|}{0.82} & \multicolumn{2}{|c|}{0.68} \\
\hline P_I & & 944.67 & 1581.9 & \multicolumn{2}{|c|}{0.83} & \multicolumn{2}{|c|}{0.58} \\
\hline P_2 & & 848.53 & 1212.42 & \multicolumn{2}{|c|}{0.81} & \multicolumn{2}{|c|}{0.5} \\
\hline P_II & & 430.09 & 646.67 & \multicolumn{2}{|c|}{0.7} & \multicolumn{2}{|c|}{0.19} \\
\hline P_15 & & 402.26 & 510.69 & \multicolumn{2}{|c|}{0.8} & \multicolumn{2}{|c|}{0.32} \\
\hline P_17 & & 396.19 & 428.64 & \multicolumn{2}{|c|}{0.84} & \multicolumn{2}{|c|}{0.17} \\
\hline \multicolumn{8}{|l|}{ IB } \\
\hline \multicolumn{2}{|l|}{ Volume $\left[\AA^{3}\right]$} & 1205.76 & 944.67 & 848.53 & 430.09 & 402.26 & 396.19 \\
\hline \multicolumn{2}{|c|}{ Surface $\left[\AA^{2}\right]$} & |55|.7| & 1581.90 & 1212.42 & 646.67 & 510.69 & 428.64 \\
\hline \multicolumn{2}{|l|}{ Depth $[\AA]$} & 26.89 & 33.71 & 18.22 & 16.31 & 20.06 & 23.18 \\
\hline \multicolumn{2}{|c|}{ Ellipsoid main axis ratio c/a } & 0.08 & 0.06 & 0.20 & 0.11 & 0.13 & 0.06 \\
\hline \multicolumn{2}{|c|}{ Ellipsoid main axis ratio b/a } & 0.35 & 0.19 & 0.62 & 0.15 & 0.48 & 0.19 \\
\hline \multicolumn{2}{|c|}{ Enclosure } & 0.03 & 0.14 & 0.07 & 0.25 & 0.00 & 0.00 \\
\hline \multicolumn{8}{|l|}{ IC } \\
\hline \multicolumn{2}{|c|}{ Pocket atom } & 249 & 198 & 177 & 76 & 143 & 124 \\
\hline \multicolumn{2}{|l|}{ Carbons } & 286 & 138 & 121 & 49 & 109 & 98 \\
\hline \multicolumn{2}{|l|}{ Nitrogen } & 24 & 26 & 24 & 10 & 13 & 13 \\
\hline Oxygen & & 36 & 31 & 29 & 17 & 21 & 12 \\
\hline Sulfurs & & 3 & 3 & 3 & 0 & 0 & I \\
\hline ID & & & & & & & \\
\hline Hydrogen b & onors & 19 & 30 & 21 & 14 & 4 & 12 \\
\hline Hydrogen b & cceptors & 57 & 61 & 63 & 36 & 24 & 25 \\
\hline Metals & & 0 & 0 & 0 & 0 & 0 & 0 \\
\hline Hydrophob & actions & 69 & 42 & 27 & 14 & 16 & 11 \\
\hline Hydrophob & & 0.48 & 0.32 & 0.24 & 0.22 & 0.36 & 0.23 \\
\hline IE & & & & & & & \\
\hline Apolar amir & ratio & 0.59 & 0.40 & 0.46 & 0.24 & 0.65 & 0.69 \\
\hline Polar amino & & 0.33 & 0.36 & 0.35 & 0.35 & 0.29 & 0.15 \\
\hline Positive am & ratio & 0.07 & 0.20 & 0.14 & 0.24 & 0.03 & 0.12 \\
\hline Negative an & id ratio & 0.02 & 0.04 & 0.05 & 0.18 & 0.03 & 0.04 \\
\hline IF & & & & & & & \\
\hline Alanine & ALA & 0 & 3 & I & I & 3 & 0 \\
\hline Arginine & ARG & I & 4 & I & I & I & 3 \\
\hline Asparagine & ASN & I & 3 & 2 & 0 & 0 & I \\
\hline Aspartate & ASP & I & I & I & 2 & 0 & 1 \\
\hline Cysteine & CYS & 0 & I & 0 & 0 & I & 0 \\
\hline
\end{tabular}

(Continued) 
Table I (Continued).

\begin{tabular}{|c|c|c|c|c|c|c|c|}
\hline Glutamine & GLN & I & 2 & I & 0 & 0 & 0 \\
\hline Glutamate & GLU & 0 & I & I & 1 & I & 0 \\
\hline Glycine & GLY & I & I & 0 & 0 & I & I \\
\hline Histadine & HIS & 0 & 2 & 1 & 0 & 0 & 0 \\
\hline Isoleucine & ILE & 5 & 3 & 5 & 0 & 3 & 2 \\
\hline Leucine & LEU & 10 & 3 & 4 & 0 & 3 & 5 \\
\hline Lysine & LYS & 2 & 3 & 3 & 3 & 0 & 0 \\
\hline Methionine & MET & 4 & 4 & 4 & 0 & I & I \\
\hline Phenylalanine & PHE & 3 & 2 & 1 & 0 & 5 & 3 \\
\hline Proline & PRO & 3 & 2 & 2 & I & 0 & 3 \\
\hline Serine & SER & 0 & 3 & 3 & I & 2 & 0 \\
\hline Threonine & THR & 10 & 4 & 6 & 4 & 4 & I \\
\hline Tryptophan & TRP & 0 & 0 & 0 & 1 & I & I \\
\hline Tyrosine & TYR & 2 & 2 & 1 & 1 & I & I \\
\hline Valine & VAL & 2 & I & 0 & I & 4 & 3 \\
\hline
\end{tabular}

system electrically stable, counter ions were added. Nosehoover thermostat was used to provide $300 \mathrm{k}$ temperature. Martyna-Tobias-Klienbarostate was used to maintained pressure of 1.01325 bars. The total time of MD simulation was $50 \mathrm{~ns}$. The electrostatic interactions were calculated by mesh Ewald method. ${ }^{17}$ Ligand and protein interactive behavior was analyzed through simulation interaction diagram tool in Desmond package. The density functional theory method was applied for the optimization of structures of all the three ligands. The Desmond software package results in RMSD of protein and RMSF of the residue which was further used for analysis. ${ }^{17}$

\section{Target Information}

The targets information in the form of total residues, protein chain, atoms, heavy atoms and charged atoms are shown in Figure 4A. The root mean square fluctuation (RMSF) in angstrom of target protein with a mean RMSF of protein needs not more than 2.5 angstrom as shown in Figure 4B. Protein secondary structure elements (SSE), alpha helices shown in red and beta strands shown in blue monitored through simulation are shown in Figure 4C.

\section{Ligand Information}

Ligands (B3, DZM and FLZ) information in the form of RMSD values, radius of gyrus (RG) value, intra molecular hydrogen bonds, molecular surface area (MSA), solvent accessible surface area (SASA) and polar surface area (PSA) are shown in Figure 5. Torsion region of each ligand
B3, DZM and FLZ throughout the simulation in different colors are given in Figure $6 \mathrm{~A}-\mathrm{C}$. The color marked rotatable bonds of the ligands are also given in Figure 6A-C. Each rotatable bond torsion is complemented by a dial plot Figure $6 \mathrm{~A} 1-\mathrm{C} 1$ and bar plots of the same color. In addition, the ligand in format ion-like number of atoms, atomic mass, charge, molecular formula, number of fragments and number of rotatable bonds are shown in Figure $7 \mathrm{~A}-\mathrm{C}$.

\section{Evaluation of B3 Against PTZ-Induced Seizures}

The mice were randomly allocated in four groups (each having 6 animals). After 30 minutes of treatment with NS, B3, DZM and FLZ, all the groups received a chemo-convulsant PTZ and the animal were observed for the onset of seizures, duration of seizures and percentage protection for 30 minutes. The percentage mortality was also noticed after 24 hours of PTZ administration. $^{18,19}$

\section{Evaluation of FLZ Effect on Anticonvulsant Effect of B3}

In order to explore the possible mechanism of B3 for its anticonvulsant effect, FLZ a BDZ receptor antagonist was injected 5 minutes before the administration of B3 and DZM. Following induction of convulsion in mice with i.p injection of PTZ after 35 minutes, the animals were observed for the onset of seizures, duration of seizures and percentage protection for 30 minutes. The percentage mortality was also noticed after 24 hours of PTZ. ${ }^{20}$ 


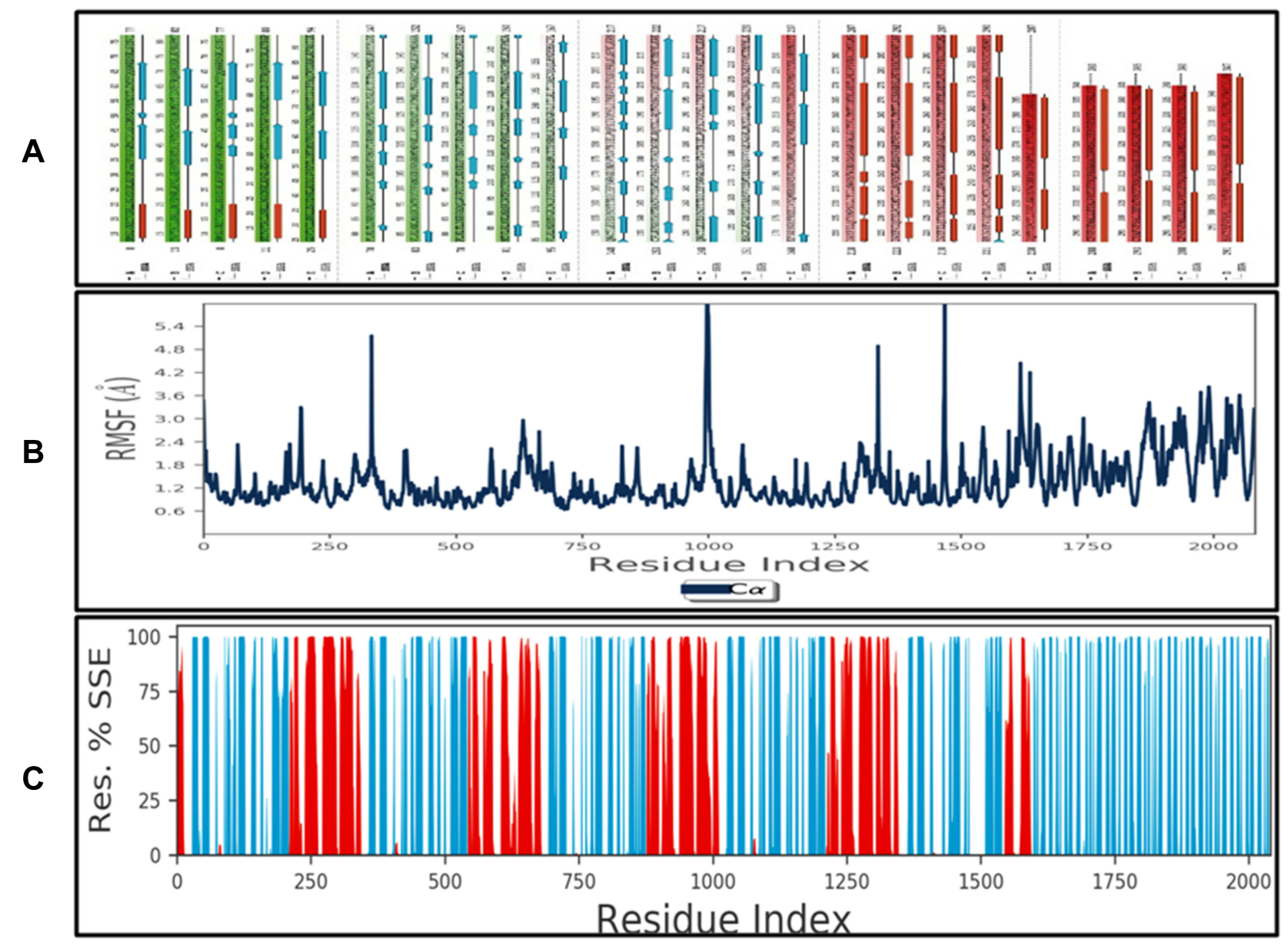

Figure 4 Part (A) represents the total residues, protein chain, atoms, heavy atoms, and charged atoms. Part (B) shows the mean root square fluctuation (RMSF) in angstrom $(\AA)$ of the target protein. Part (C) represents the protein secondary structure elements (SSE), alpha-helices shown in red, and beta-strands shown in blue monitored through simulation. The plot summarizes the SSE composition for each trajectory frame over the course of simulation.

\section{Biochemical Investigation LPO Assay}

Lipid hydroperoxide assay was carried out by colorimetric method for the determination of thiobarbituric acid reactive substances (TBARS). ${ }^{21}$ According to this assay $200 \mathrm{uL}$ supernatant of the homogenized samples was mixed with $200 \mathrm{uL}$ ascorbic acid, $20 \mathrm{uL}$ ferric chloride and $580 \mathrm{~mL}$ phosphate buffer. The mixture was incubated at $37{ }^{\circ} \mathrm{Cfor} 1$ hour. After this step, $1000 \mathrm{uL}$ of each $0.66 \%$ thiobarbituric acid and $10 \%$ trichloroacetic acid was added to halt reaction. The samples tubes were then passed through water at $25^{\circ} \mathrm{C}$, then cold water and centrifuged at $3000 \times \mathrm{g}$ for 10 minutes. The concentration of TBARS $-\mathrm{Nm} / \mathrm{min} / \mathrm{mg}$ protein was calculated by collecting and measuring the supernatant at $535 \mathrm{~nm}$.

\section{Nitric Oxide Assay}

NO assay was carried out according to the already established methodology. ${ }^{22}$ According to this protocols, supernatant $(50 \mathrm{uL})$ and Griess reagent $(50 \mathrm{uL})$ were mixed together. This reagent consists of 5\% phosphoric acid, $0.1 \%$ naphthyleethylenedaiamine dihydrochloride and $1 \%$ sulfanilamide in distilled water. Incubated the mixture at $37^{\circ} \mathrm{C}$ for 30 minutes and then processed for the reading on micro plate reader (Bio-ELx 808). The absorbance coefficient was calibrated by using sodium nitrate solution.

\section{Estimation of Oxidative Stress}

The damaged caused by PTZ is find out by the determination of oxidative stress markers. The sample (cortex) after homogenization in phosphate buffer containing phenylmethylsulfonyl fluoride (PMSF) as protease 


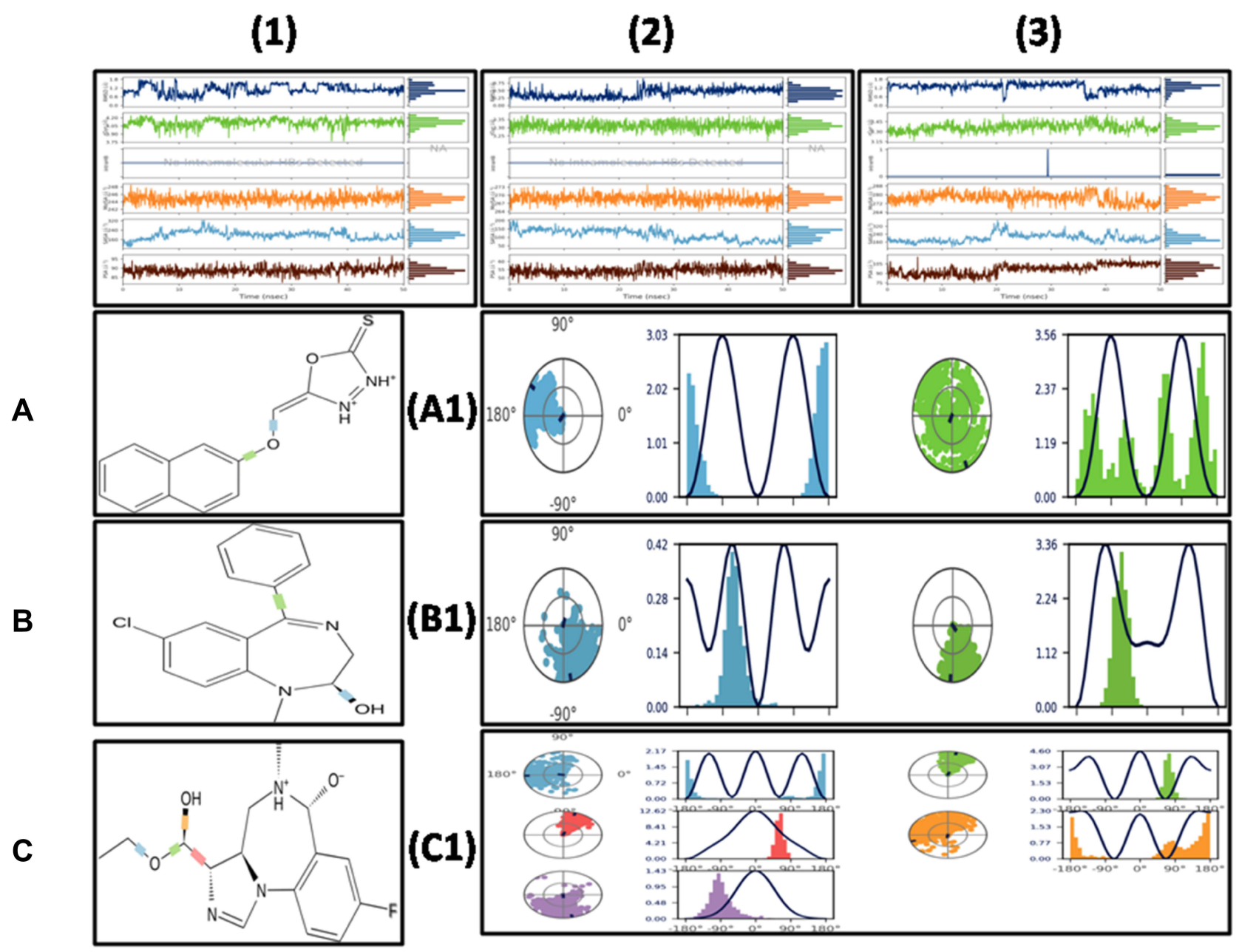

Figure 5 Parts (1), (2), and (3) represent ligands (5-[(naphthalen-2-yloxy) methyl]-I,3,4-oxadiaszole2-thiol [B3], diazepam [DZM], and flumazenil [FLZ]) root mean square deviation (RMSD) values, radius of gyrus (RG) value, intra molecular hydrogen bonds, molecular surface area (MSA), solvent accessible surface area (SASA), and polar surface area (PSA), respectively. Parts (A-C) represent the torsion region of each ligand B3, DZM and FLZ throughout the simulation shown in different colors. (AI-AC) represent rotatable bonds. Each rotatable bond torsion is complemented by a dial plot $(\mathbf{A I}-\mathbf{C I})$ and bar plots of the same color.

blocker, was centrifuged at $4000 \times \mathrm{g}$ for $10 \mathrm{~min}$ at $4^{\circ} \mathrm{C}$ and collected the supernatant. ${ }^{23}$ For determination of GST level, the supernatant $(0.2 \mathrm{~mL})$ was mixed with a $2 \mathrm{~mL}$ solution of sodium phosphate $(0.2 \mathrm{M})$ and DTNB $(0.6 \mathrm{Mm})$. About $3 \mathrm{~mL}$ phosphate buffer was added to mark up the volume and then incubated for $10 \mathrm{~min}$ at room temperature. Spectrophotometer was used for the absorbance measurement at $412 \mathrm{~nm}$. Solution of phosphate buffer and DTNB was used as control. The value obtained from the subtraction of control absorbance from that of sample containing tissue was considered as real absorbance which denotes GSH level showed in umol/mg of proteins. The GST level was find out according to protocol as used earlier. ${ }^{24}$ The supernatant $(60 \mathrm{uL})$ was poured into $1.2 \mathrm{~mL}$ of freshly formulated solution $(5 \mathrm{mM}$ GSH, $1 \mathrm{mM} \mathrm{CDNB}$ in phosphate buffer of $0.1 \mathrm{M}$ ) in triplets via glass vials. From mixture a $210 \mathrm{uL}$ was putted into micro plate and rate of reaction was found with the help of ELIZA microplate reader (Bio-Tek ELx-808, Winooski, VT, USA) at $340 \mathrm{~nm}$. Instead of tissue, $60 \mathrm{uL}$ of water was added which acted as control. The GST was expressed as umol of CDNB conjugate $/ \mathrm{min} / \mathrm{mg}$ of proteins.

\section{Histopathological Examination Hematoxylin and Eosin ( $\mathrm{H}$ and $\mathrm{E})$ Staining}

$\mathrm{H}$ and $\mathrm{E}$ staining was performed according to the established and well explained protocol. ${ }^{25}$

\section{Immuno Histopathological Evaluation}

Immunohistochemical study was carried out according to the already enlightened protocol explained. ${ }^{26}$ 


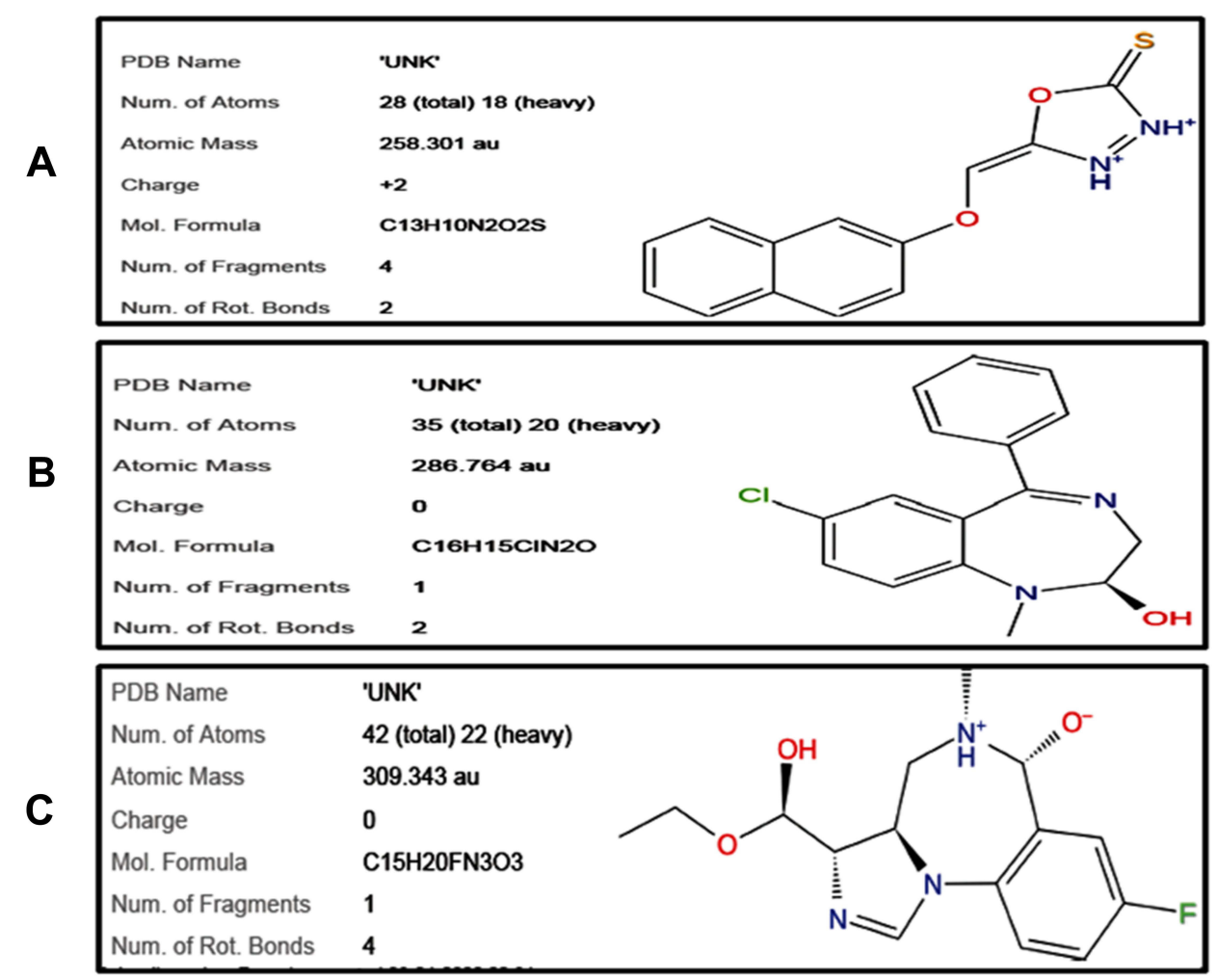

Figure 6 (A-C) represent ligands (5-[(naphthalen-2-yloxy) methyl]-I,3,4-oxadiaszole2-thiol [B3], diazepam [DZM], and flumazenil [FLZ]) information in the form of number of atoms, atomic mass, charge, molecular formula, number of fragments and number of rotatable bonds.

\section{ELISA}

ELISA kit was used for finding out the expression of inflammatory marker TNF- $\alpha$ in the cortex of brain. In 96 well-plates, the brain cortex supernatant was treated with the designated antibodies and then ELISA micro-plate reader was used to find the expression degree of inflammatory markers ie, TNF- $\alpha$. The values were denoted as pictograms/milliliter $(\mathrm{pg} / \mathrm{mL})$. The procedure was repeated in triplicate. $^{27}$

\section{Statistical Analysis}

Data are showed as mean \pm SEM. $\mathrm{H}$ and $\mathrm{E}$ staining, IHC staining, behavioral data, oxidative stress data and ELISA were analyzed using One Way ANOVA, followed by the post-hoc Tukey's test in Graph Pad Prism. The morphological data was analyzed by using Image J-software. $\mathrm{P}$ value was calculated through Graph Prad prism Sign $* * *$ and $* * *$ Represents significant difference values $\mathrm{P}<$ $0.05,0.01$ and 0.001 respectively.

\section{Results}

\section{Pharmacokinetic Profile of B3}

The pharmacokinetic profile of B3 is shown in Table 2.

\section{Docking Analysis}

The best pose of the ligand molecules B3, DZM, and FLZ against target proteins GABA are shown in Figures $5 \mathrm{~A}, 8 \mathrm{~A}$ and $9 \mathrm{~A}$. The interaction of the ligands is shown in Figure $5 \mathrm{~B}, 8 \mathrm{~B}$ and $9 \mathrm{~B}$, and the hydrogen bonds are shown in Figure 5C, 8C and 9C. B3 with the highest binding affinity $(6.3 \mathrm{kcal} / \mathrm{mol})$ formed four hydrogen bonds. DZM and FLZ formed one and two hydrogen bonds with binding affinity of $5.7 \mathrm{kcal} / \mathrm{mol}$ and $5.3 \mathrm{kcal} / \mathrm{mol}$ respectively. The hydrogen bonds number, binding energies ( $\mathrm{kcal} / \mathrm{mol})$, and residues of amino acid involved in the interactions of B3, DZM, and FLZ are summarized in Table 3.

\section{Molecular Dynamic (MD) Simulation Analysis}

MD simulation was performed using the Desmond software package. All the complexes were run for 50ns to obtain the results after providing physiological environment to the complexes. The root mean square fluctuations (RMSF) of B3, DZM, and FLZ are shown in Figure 10AC. The stability of the ligand receptor complex can be 


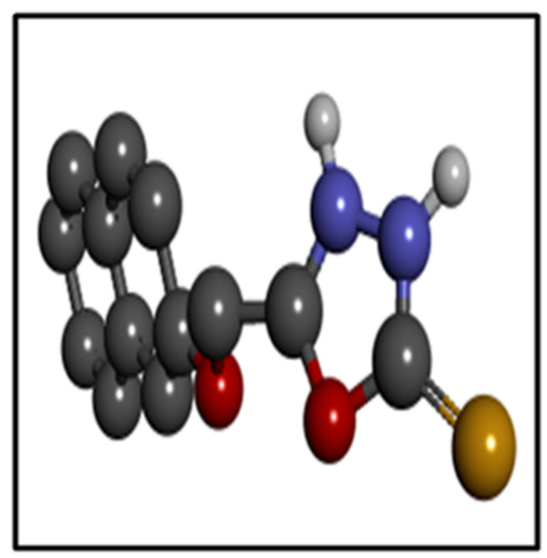

A

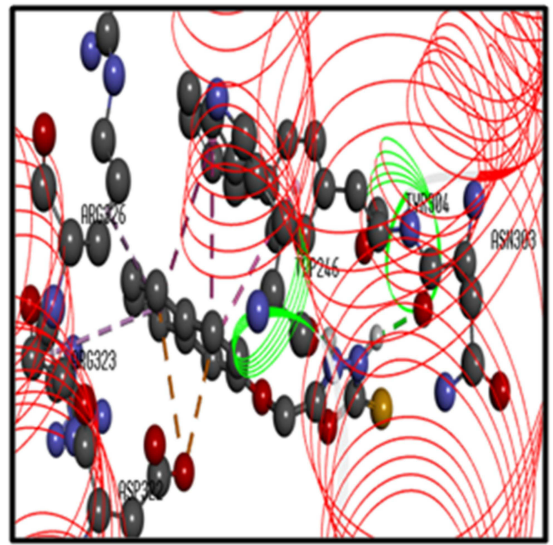

B

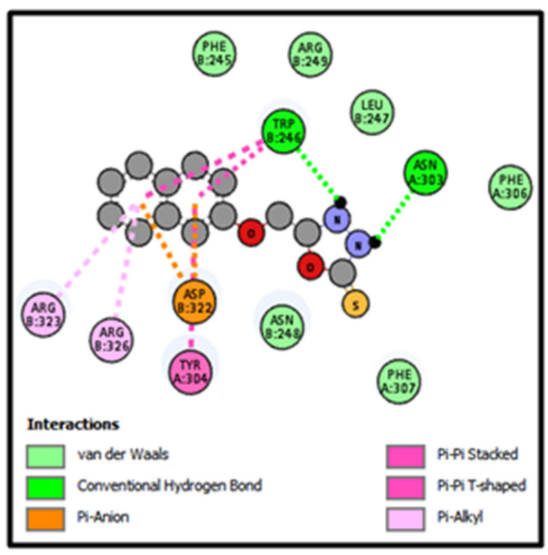

C

Figure 7 Best pose of B3 (A), interactions of B3 (B) and two-dimensional representation of hydrogen bonds of B3 (C) drawn using Discovery Studio Visualizer 2016.

predicted by the RMSD values as shown in Figure 11 . Little variation in the RMSD shows more stable binding. The RMSD of the B3, DZM, and FLZ, and targets are shown in 11 ( $a, b$ and $c)$. The representation of the interactions in the form of H-bonds, hydrophobic, ionic, and water bridges are shown in Figure 12A1-A3. The top panel shows the total number of specific contacts of the ligand and protein shown in blue color. The bottom panel (orange color) represents the interaction of the ligand with the exact residue of the target. Protein interactions with the ligand were monitored throughout the simulation. These interactions are shown in Figure 12B1-B3. The schematic detail of the ligand-atom interactions with protein-residues are shown in Figure 12C1-C3. The quantitative analysis of the MD simulation specifically for the ligand B3 and DZM an agonist of GABA receptor showed that B3 forms hydrogen bond with aspartate (ASP) 56 (95\%), threonine (THR) 133 (70\%). DZM was found interacting at similar points and makes hydrogen bonds at ASN, THR, SER and ILE. The data presented as is complying with the previously published data. ${ }^{16,17}$

\section{Effect of B3 on PTZ-Induced Seizures}

Administration of intraperitoneal (i.p) injection of B3 at 20 and $40 \mathrm{mg} / \mathrm{kg}$ resulted in the protection of $50.0 \%$ and $83.33 \%$ of animal respectively in PTZ-induced mortality. In addition, $\mathrm{B} 3$ also significantly increased the onset time of seizures with $\mathrm{P}<0.01$ and decreased the duration of seizures with $\mathrm{P}<0.01$ in $\mathrm{PTZ}$-induced seizures. $\mathrm{B} 3$ also reduced the mortality to $16.66 \%$ and increased the protection $(83.33 \%)$ as compared to $100 \%$ mortality and $0 \%$ protection in the PTZ group as shown in Table 4. The result obtained from anticonvulsant studies of B3 is complying with the recently published data by Van and their colleague who explained the PTZ-induced epilepsy in mice as animal model. ${ }^{28}$ 
Table 2 Represent the Pharmacokinetics Profile of Ligand 5-[(naphthalen-2-yloxy) methyl]-I,3,4-oxadiaszole2-thiol (B3

\begin{tabular}{|c|c|c|c|c|c|}
\hline \multicolumn{2}{|l|}{ Medicinal Chemistry } & \multicolumn{2}{|l|}{ Water Solubility } & \multicolumn{2}{|c|}{ Drug Likeness } \\
\hline Formula & $\mathrm{Cl} 3 \mathrm{HION} 2 \mathrm{O} 2 \mathrm{~S}$ & Class & Soluble & Lipinski & Yes \\
\hline Lead likeliness & Yes & Solubility & $\begin{array}{c}4.66 \mathrm{e}-02 \mathrm{mg} / \mathrm{mL} \\
1.8 \mathrm{e}-04 \mathrm{~mol} / \mathrm{L}\end{array}$ & Ghose & Yes \\
\hline Synthetic Accessibility & 2.37 & $\log S(E S O L)$ & 3.74 & Veber & Yes \\
\hline Pain Assay Interface Structures & 0 alert & Pharmacokinetic Properties & & Egan & Yes \\
\hline Molecular weight & $258.30 \mathrm{~g} / \mathrm{mol}$ & Gl absorption & High & Muegge & Yes \\
\hline No of heavy atoms & 15 & Pg substrate & No & Bioavailability score & 0.55 \\
\hline No of $\mathrm{H}$ bonds acceptor & 4 & CYP IA2, CYP 2C9, CYP 2C19, CYP3A4 & Yes & Log kp Skin permeation & $\begin{array}{c}-5.75 \mathrm{sm} / \\
\mathrm{s}\end{array}$ \\
\hline Molecular refractivity & 70.04 & CYP 2D6 & No & $\begin{array}{l}\text { Topological Polar Surface } \\
\text { Area }\end{array}$ & 86.95 \\
\hline
\end{tabular}

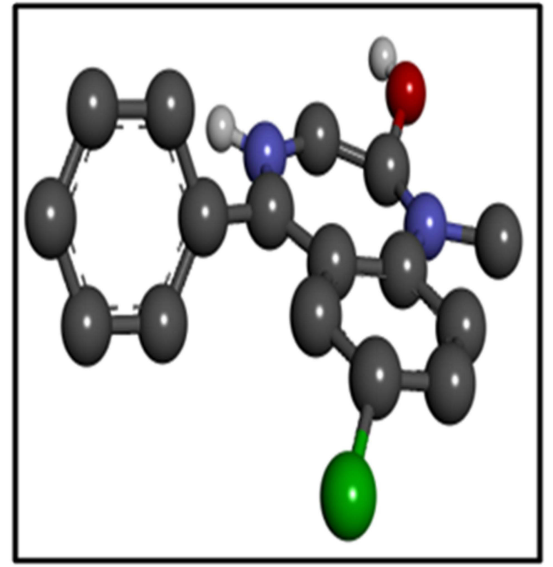

A

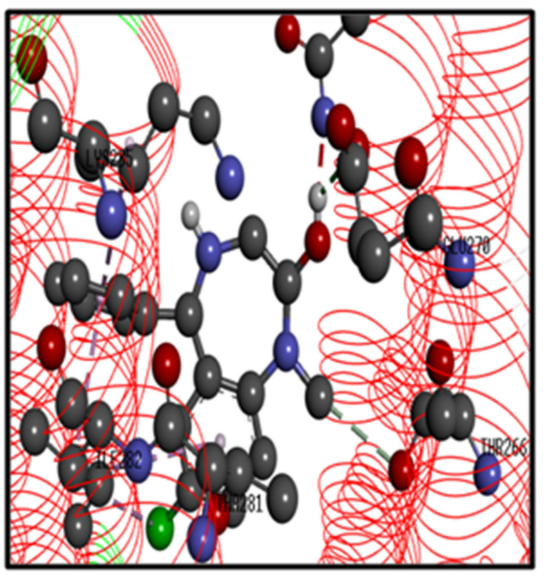

B

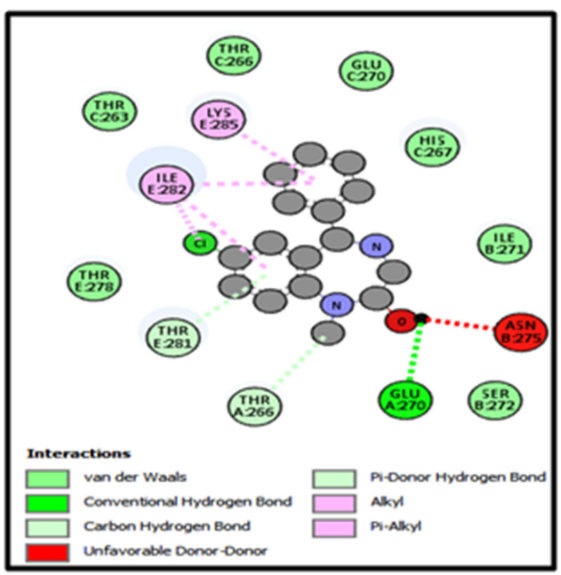

C

Figure 8 Best pose of diazepam (DZM) (A), interactions of DZM (B) and two-dimensional representation of hydrogen bonds of DZM (C) drawn using Discovery Studio Visualizer 2016. 


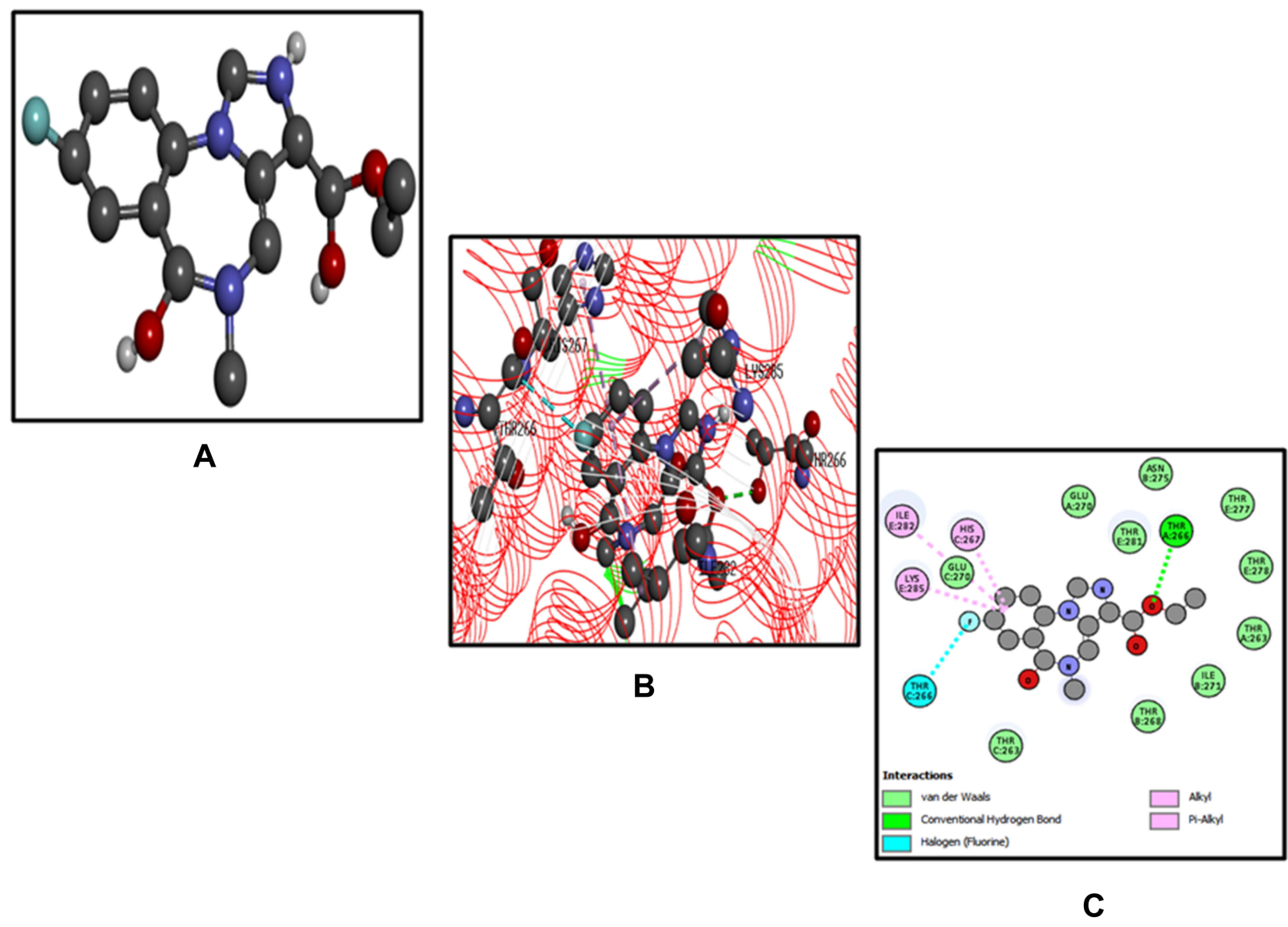

Figure 9 Best pose of flumazenil (FLZ) (A), interactions of FLZ (B) and two-dimensional representation of hydrogen bonds of FLZ (C) drawn using Discovery Studio Visualizer 2016 .

\section{Effect of Flumazenil on Anticonvulsant Effect of B3}

Administration of i.p injection of FLZ at $2 \mathrm{mg} / \mathrm{kg} 5$ minutes before B3 and 35 minutes before PTZ resulted in inhibition of the percentage protection to $66.6 \%$ from $83.33 \%$ in PTZinduced mortality. FLZ also significantly decreased ( $\mathrm{P}<$ $0.01)$ the onset time of seizures and increased the duration of seizures $(\mathrm{P}<0.01)$. Administration of flumazenil also increased the mortality to $33.3 \%$ as compared to saline $(100 \%)$ as shown in Table 5.

\section{Effect on LPO and Nitric Oxide}

The B3 was evaluated for its effect against lipid peroxidation (LPO) and inducible nitric oxide synthase (iNOS) in brain cortex. The oxidative stress markers are the prominent molecules responsible for promoting inflammation and neurodegeneration. ${ }^{29}$ Several studies explain the up regulation of such damaging factors which are involved in increasing the potential of harmful consequences. B3 significantly decreased the level of both iNOS $(46.41 \pm 2.6)$ and LPO (187.16 \pm 3.1) with $\mathrm{P}<0.01$ and $\mathrm{P}<0.001$ compared to the saline group, iNOS $(70.22 \pm 1.2)$ and LPO $(253.13 \pm 3.1)$ as shown below in Table 6 .

\section{Effect on the Oxidative Stress Enzyme}

B3 was investigated for its effect against certain oxidative stress-related enzymes like GSH and GST in brain cortex as shown in Table 6. The level of GSH and GSH in PTZ-induced convulsion group was $7.22 \pm 4.2$ and $5.88 \pm 2.3$ respectively. Treatment of $\mathrm{B} 3$ significantly increased $(\mathrm{P}<0.01)$ the level of both the GSH and GST to $47.26 \pm 1.2$ and $69.78 \pm 2.6$, respectively. The results of B3 showing the effect on modulation of protective biomarkers and reversing the signs of epileptic shock are well studied markers for their role in neurodegenerative ailments. ${ }^{29}$ 
Table 3 Binding Affinity (Kcal/mol) of Hydrogen Bonds, Amino Acid Residues Pi Alkyl Bonds, Van der Waals forces After Docking of 5-[(naphthalen-2-yloxy) methyl]-I,3,4-oxadiaszole2-thiol (B3), Diazepam (DZM), and Flumazenil (FLZ) Against Gamma Amino Butyric Acid (GABA)

\begin{tabular}{|l|c|c|c|c|c|c|c|}
\hline Name & \multicolumn{7}{|c|}{ GABA (6D6T) } \\
\cline { 2 - 8 } & $\begin{array}{c}\text { Binding } \\
\text { Affinity }\end{array}$ & $\begin{array}{c}\text { Hydrogen } \\
\text { Bonds }\end{array}$ & $\begin{array}{c}\text { Amino Acid } \\
\text { Residues }\end{array}$ & $\begin{array}{c}\text { Pi Alkyl } \\
\text { Bonds }\end{array}$ & $\begin{array}{c}\text { Amino } \\
\text { Acid } \\
\text { Residues }\end{array}$ & $\begin{array}{c}\text { Van der } \\
\text { Waals } \\
\text { forces }\end{array}$ & Amino Acid Residues \\
\hline B3 & 6.3 & 2 & $\begin{array}{c}\text { ASN } 303 \\
\text { TRP } 246\end{array}$ & 2 & TRP 304 & 6 & $\begin{array}{c}\text { ASN 248, ARG 249, LEU 247, PHE 245, PHE } \\
306, \text { PHE 307 }\end{array}$ \\
\hline DZM & 5.7 & 1 & THR 6I & - & - & 8 & $\begin{array}{c}\text { ASN 54, ARG I36, ARG I87, GLU 59, GLY } \\
5 \text { I, PRO 52, SER 54, THR I34 }\end{array}$ \\
\hline FLM & 5.3 & 2 & $\begin{array}{c}\text { ASN III } \\
\text { VAL 106 }\end{array}$ & I & PHE 105 & 7 & $\begin{array}{c}\text { HIS I 10, LYS I02, LYS I03, LYS I06, LYS II2, } \\
\text { VAL I08, SER 104 }\end{array}$ \\
\hline
\end{tabular}

\section{Effect of Histo-Pathological Changes (Hematoxylin and Eosin Staining)}

Morphological alteration in brain tissue after administered of PTZ is a well-known reported parameter explaining the damage to the affected area. Administration of PTZ results in increased infiltration, disturbance in cellular structure, edema formation, increased intracellular spaces, and disorganized pattern as shown in Figure 13. Treatment with B3 $(40 \mathrm{mg} / \mathrm{kg})$ reverses the PTZ induced pathological changes and results in a well-organized cellular structure, without infiltration, and intact intracellular spaces free from edema. The results of the current study are in compliance with the results of the already published literature. ${ }^{30}$

\section{Effect on Immunohistochemistry Changes (IHC Staining)}

The results of immunohistochemistry are shown in Figure 14A and B. Results demonstrated marked elevation/expression of the TNF- $\alpha$ in case of the PTZinduced group. B3 administration attenuated the over expressed level of TNF- $\alpha$, significantly $(\mathrm{P}<0.001)$ in the cortex. The results are in accordance the previous literature. $^{30}$

\section{Effects on the Inflammatory Marker (ELISA)}

We investigated the B3 effects on expression of TNF- $\alpha$ in the cortex as shown in Figure 15. Over expressed level of TNF- $\alpha$ in the PTZ group was seen in cortex. B3 administration significantly $(\mathrm{P}<0.001)$ down regulated $\mathrm{TNF}-\alpha$ and reduced the sign of convulsion suppressing PTZ- induced inflammation. The results obtained can be correlated with the already published data. ${ }^{30}$

\section{Discussion}

In order to improve the patient quality of life (QOL) and reduce the burden of disease some commonly used drugs are available in the market comprising carbamazepine, phenobarbital, phenytoin, diazepam, etc. for managing the seizures attacks, however, utilization of these agents is also linked with gastrointestinal problems, dizziness, somnolence, and addictive potential. Moreover, it has also been found that these agents are ineffective in $30 \%$ of the population. Hence, the health system needs to develop safe and effective agents for epilepsy to improve patient QOL. ${ }^{31}$ Epilepsy is neurological disease described by frequent and unpredictable disturb electrical discharges that affected 50 million people, irrespective of age, across the globe. The mechanism of epilepsy is not yet clear but it is postulated that infections, neuroinflammation, and stroke or disturbance in GABA and glutamate pathways may cause epileptic shock. GABA has been a well-known target of epilepsy and is the point of focus and discussion of many researchers from decades. Pyrimidine-trizine newly synthesized compounds were recently researched for their potential in attenuating the seizures attacks by their GABA mimetic action. ${ }^{32}$ This study was also designed in order to develop and add a new moiety having anti-epileptic activity mediated through GABA receptors. GABA with PDB-ID: 6D6T is also used in previous research in computational studies by many researchers. ${ }^{33}$ Based on literature study and evidences about GABA for its involvement in seizures we also select it in our study. In 


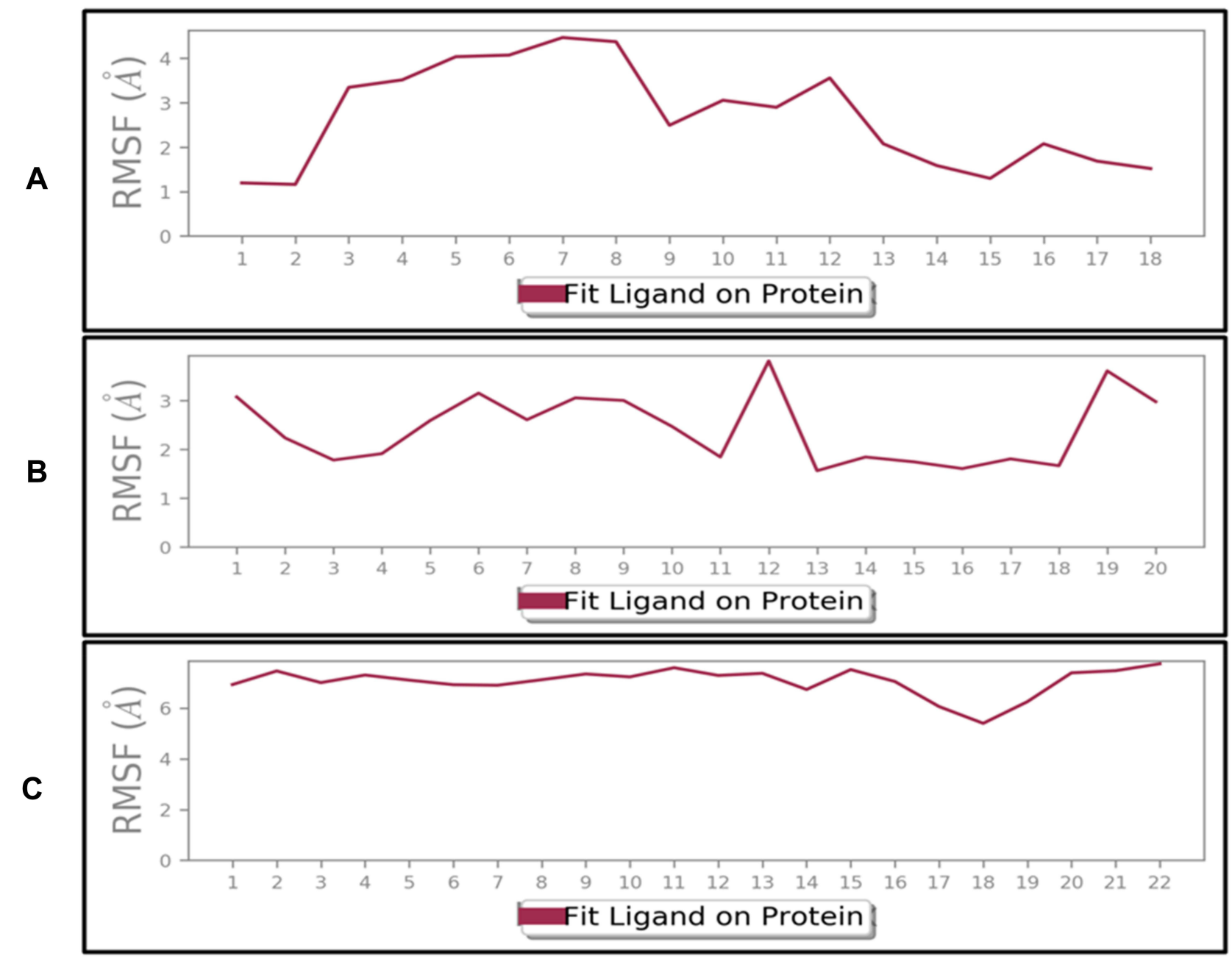

Figure 10 (A-C) represents the root mean square fluctuation (RMSF) of the atomic positions for the ligand 5-[(naphthalen-2-yloxy) methyl]-I,3,4-oxadiaszole2-thiol (B3), diazepam (DZM), and flumazenil (FLZ) using the Desmond package.

order to evaluate the effect of B3 in epileptic shock primarily the ligand B3 and GABA were screened through molecular docking studies. Molecular docking was conducted to check out the binding affinity of the ligand with GABA. Nowadays docking is a preliminary step to first confirm the interaction of ligand with its respective target. ${ }^{10,11}$ The favorable results of docking in the form of binding affinities and hydrogen bonds was the reason to perform molecular dynamics (MD) simulation for further validation interaction of $\mathrm{B} 3$ against GABA. MD simulation is gaining attention of researcher involved in drug discovery and development. ${ }^{34}$ This tool can be utilized in checking conformational changes, positioning of various atomic structure, detect mutation and protonation and phosphorylation and more interestingly the interactions of any atom, target or ligand with its surroundings. ${ }^{35}$ The MD simulation was first used in 1970 and later on attract many biologists to screen their newly developed/discovered compound through MD simulation. It was used by many researchers in order to brought comparison and correlation of results obtained from animal studies. ${ }^{36,37}$ It is also utilized in neurosciences to detect the neuronal signaling pathways, their working and how these pathways are altered to develop a disease condition and how to target it to reverse the pathological process. ${ }^{38-40} \mathrm{We}$ also perform MD simulation of three complexes for 50ns. Complexes were validated for the stability, implementing a MD simulation using Desmond software package for 50 ns. The complexes were found stable and presenting in range RMSF and RMSD value with favorable interaction determining the affinity of the ligands to its targets. The obtained results of docking and MD simulation were in line with the already published data and hence we perform animal studies. ${ }^{15-17}$ In animal studies various types of 


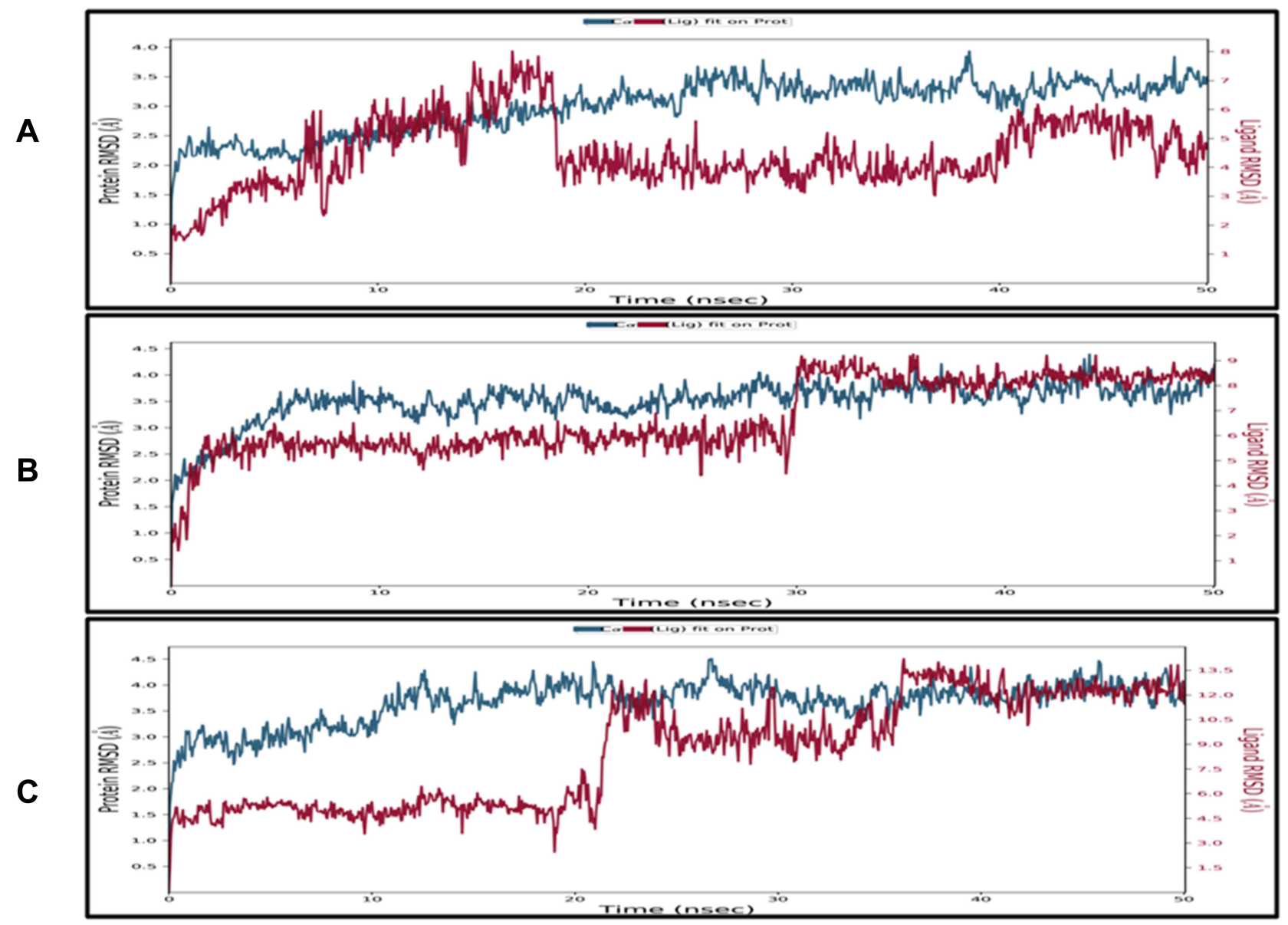

Figure II (A-C) represents root mean square deviation (RMSD) for protein GABA (6D6T) shown in blue and RMSD of ligands including 5-[(naphthalen-2-yloxy) methyl]I,3,4-oxadiaszole2-thiol (B3), diazepam (DZM) and flumazenil (FLZ) as shown in red using the Desmond software package.

chemo convulsant agent are used in animal's model to explore the effect of synthetic or agents obtained from natural sources. ${ }^{18,41}$ We select PTZ-induced acute epileptic model to investigate the effect of B3 in acute epileptic shock. PTZ is a BDZ receptor antagonist and is a chemoconvulsant agent that is associated with the up regulation of various types of inflammatory mediators IFMs like interleukin-6 (IL-6), TNF- $\alpha$, interleukin-1 $\beta$ (IL-1 $\beta$ ), interleukin-10 (IL-10), and interferon gamma (INF- $\gamma$ ) in the hippocampus and cerebral cortex. ${ }^{42,43}$ The involvement of pro-inflammatory cytokines including IL-6, interleukin-17 (IL-17) and IL-17 receptors (IL-17R), and TNF- $\alpha$ has also demonstrated their role in disruption of BBB and induction of seizures. The primary cells for the production of these IFMs are called glial cells of the brain, and are involved in the pathogenesis of many neurological disorders. ${ }^{44-46}$ TNF- $\alpha$ activates TNF receptors- 1 and 2 (TNFR1 and TNFR2). TNFR1 and TNFR2 are the receptors with hyper excitation/ictogenic and antiictogenic properties.
PTZ injection, bacterial or viral infection results in activation of the TNFR1, and hence, results in the excitation of neuronal cells and epilepsy. ${ }^{47}$ The involvement of IFMs in neuro-inflammatory and neurodegenerative diseases has been extensively studied in the past. ${ }^{48}$ These IFMs play a crucial role in disease development and pathogenicity of two important regions of the brain such as the cortex and the hippocampus that are readily affected under such neuronal crises. ${ }^{49,50}$ In order to cope up with worse circumstances, anti-inflammatory agents are the most commonly used agents to reverse the pathogenic state, and to limit the release of IFMs consequently correcting the behavioral deficits. ${ }^{51}$ Among the various classes effective in the neurodegeneration and neuroinflammation, oxadiazoles play an important and promising class of synthetic origin attenuating various kind neuroinflammation in neurodegenerative diseases. Oxadiazole is a biologically active moiety possessing five membered heterocyclic ring structures. The agents of this class have promising anti- 
A
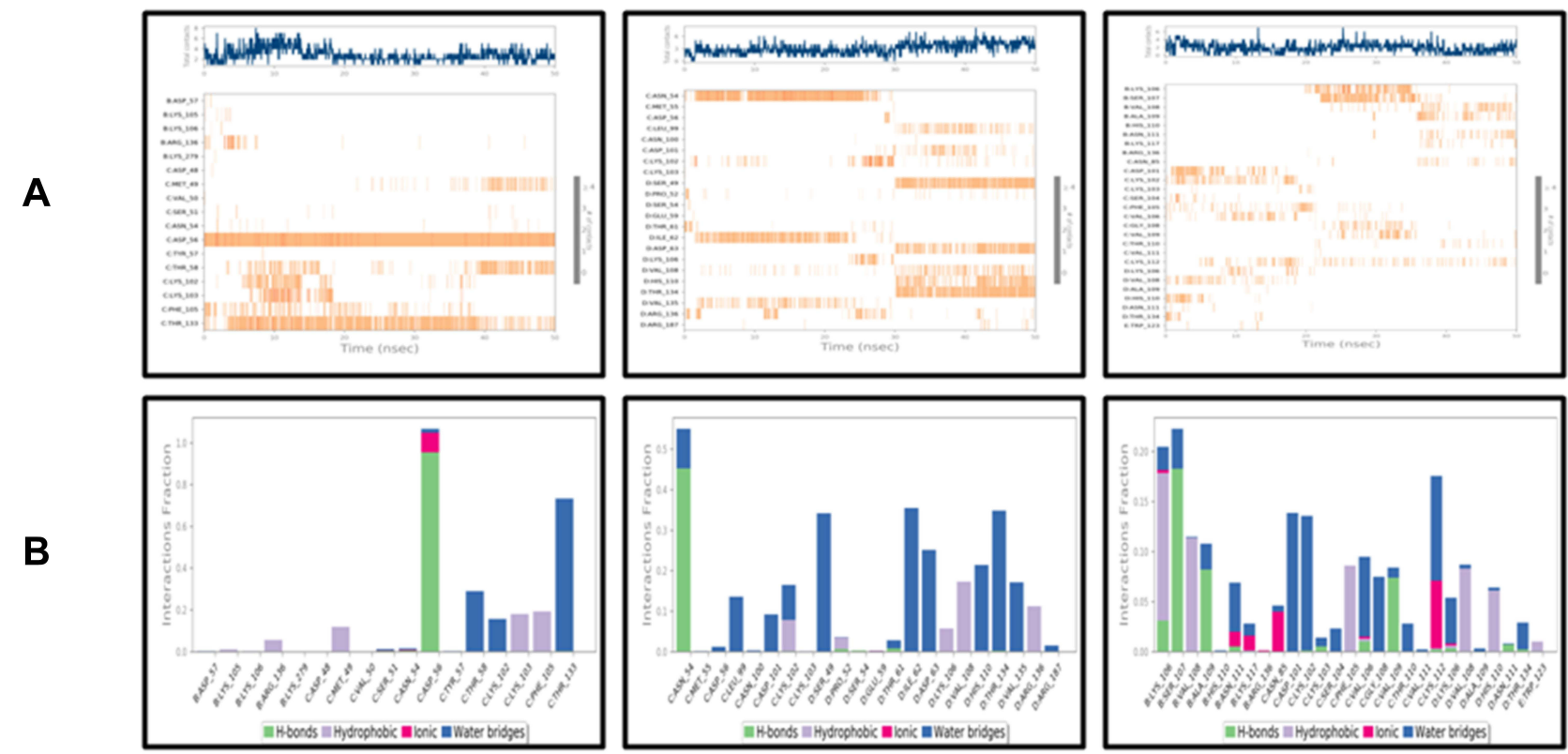

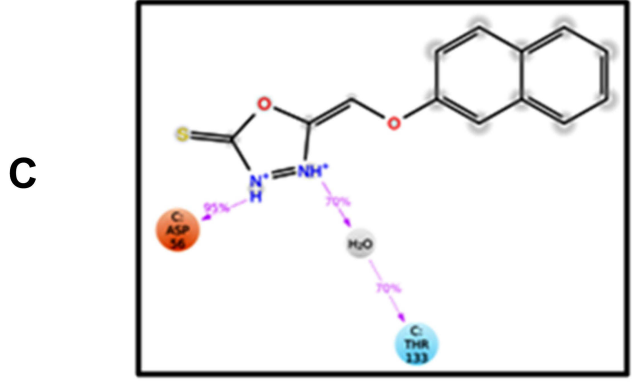

(1)

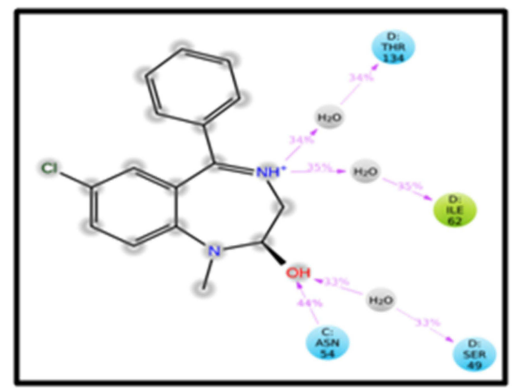

(2)

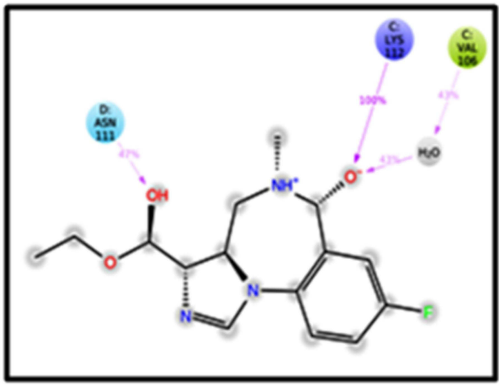

(3)

Figure 12 A timeline representation of the interactions and contacts (hydrogen bonds, hydrophobic, ionic, and water bridges) are displayed in (AI-A3). The top-panel displays the total count of the specific contacts of the protein with the ligand. The bottom-panel shows the interacting residues with the ligand. Some residues form more than one specific contact with the ligand, denoted by a darker-shade of Orange, according to the scale to the right of the plot. Protein interactions with the ligand are shown in (B I-B3). These interactions are categorized as hydrogen bonds, hydrophobic, ionic, and water bridges. Schematic detail of the ligand-atom interactions with the protein residues. Interactions that occurred more than $30 \%$ of the simulation time are shown in $(\mathbf{C I}-\mathbf{C} 3$ ).

inflammatory, analgesic, and anti-oxidant potential. ${ }^{10,11}$ Recently this class of active agents has been also researched for its attenuating potential of middle cerebral artery occlusion-induced stroke. ${ }^{52}$ The agents belonging to oxadiazoles are also researched for anti-Alzheimer potential, anticancer, antimicrobial, anti-inflammatory, anti-allodynic properties, and anti-insomnia. ${ }^{53-55}$ In animal studies it has been found that B3 administration results in correction of behavioral deficit by increasing onset time of seizures and reducing the seizures duration as shown in result section. In molecular studies as confirmed from the literature study that PTZ is involved in increasing expression of nitric oxide, lipid peroxidase and $\mathrm{TNF}-\alpha$, which are the reason of mediating epileptic shock. B3 down

Table 4 Effect of I,3,4 Oxadiazole Derivative (B3) on Phenyltetrazole (PTZ)-Induced Seizure in Mice. Data are Showed as Mean \pm Standard Error of Mean (SEM) $(n=6)$. **P < 0.01 vs PTZ Group, One-Way Analysis of Variance (ANOVA) and Post Hoc Tukey's Test

\begin{tabular}{|l|c|c|c|c|}
\hline Groups & \%Protection (30 $\mathbf{~ m i n})$ & Seizure Onset (s) & Seizure Duration (s) & Mortality (24 h) \\
\hline PTZ + NS & 0.0 & $76.58 \pm 4.67$ & $35.78 \pm 4.12$ & 100 \\
PTZ + DZM & 100 & $1534.54 \pm 5.80$ & $2.45 \pm 2.10$ & 0.0 \\
PTZ + B3 (20mg/Kg) & 50.0 & $645.32 \pm 6.62^{* *}$ & $17.91 \pm 4.60^{* *}$ & 50.0 \\
PTZ + B3 (40mg/Kg) & 83.33 & $1135.41 \pm 4.24^{* *}$ & $12.66 \pm 5.10^{* *}$ & 16.66 \\
\hline
\end{tabular}

Abbreviations: NS, normal saline; FLZ, flumazenil; DZM, diazepam; B3, 5-[(naphthalen-2-yloxy) methyl]-I,3,4-oxadiaszole2-thiol. 
Table 5 Effect of Flumazenil on Anticonvulsant Effect of I,3,4 Oxadiazole Derivative (B3) in Phenyltetrazole (PTZ)-Induced Seizure in the Presence of Flumazenil in Mice. Data are Showed as Mean \pm Standard Error of Mean (SEM) $(N=6)$. ${ }^{* * P}<0.01$ and***P<0.00I vs PTZ Group, One-Way Analysis of Variance (ANOVA) and Post Hoc Tukey's Test

\begin{tabular}{|l|r|c|c|c|}
\hline Groups & \%Protection (30 $\mathbf{~ m i n )}$ & Seizure Onset (s) & Seizure Duration (s) & Mortality (24 hr) \\
\hline PTZ + NS & 0.0 & $76.58 \pm 4.67$ & $35.78 \pm 4.12$ & 100.0 \\
PTZ + FLZ & 0.0 & $95.50 \pm 6.72$ & $25.83 \pm 2.12$ & 100.0 \\
PTZ + DZM & 100.0 & $1534.54 \pm 5.80 * * *$ & $2.45 \pm 2.10 * * *$ & 0.0 \\
PTZ + FLZ + DZM & 33.33 & $228.62 \pm 6.33$ & $42.54 \pm 2.28$ & 66.66 \\
PTZ + B3 (40mg/Kg) & 83.60 & $1135.41 \pm 4.24 * *$ & $12.66 \pm 5.10 * *$ & 16.6 \\
PTZ + FLZ + B3 & 66.6 & $194.93 \pm 5.28 * *$ & $28.86 \pm 3.06$ & 33.3 \\
\hline
\end{tabular}

Abbreviations: NS, normal saline; FLZ, flumazenil; DZM, diazepam; B3, 5-[(naphthalen-2-yloxy) methyl]-1,3,4-oxadiaszole2-thiol.

Table 6 Express Effects of 5-[(naphthalen-2-yloxy) methyl]-I,3,4-oxadiaszole2-thiol (B3) on Oxidative Enzymes of the Brain Cortex in Acute Epileptic Model. Data are Showed as Mean \pm Standard Error of Mean (SEM) $(n=6)$ ). *P $<0.05$, **P $<0.01$ and***P $<0.001$ vs PTZ Group, One-Way Analysis of Variance (ANOVA) and Post Hoc Tukey's Test

\begin{tabular}{|l|c|c|l|c|}
\hline Groups & GSH & GST & iNOS & LPO \\
\hline PTZ + NS & $7.22 \pm 4.2$ & $5.88 \pm 2.3$ & $70.22 \pm 1.2$ & $253.13 \pm 3.1$ \\
PTZ + B3 & $47.26 \pm 1.2^{* *}$ & $69.78 \pm 2.6^{* *}$ & $46.41 \pm 2.6^{*}$ & $187.16 \pm 3.1^{*}$ \\
PTZ + DZM & $69.42 \pm 2.2^{* *}$ & $77.33 \pm 1.4^{* *}$ & $26.12 \pm 1.7^{* *}$ & $82.26 \pm 1.8^{* * *}$ \\
PTZ + FLZ & $5.23 \pm 2.8$ & $6.33 \pm 2.5$ & $76.20 \pm 1.8$ & $263.76 \pm 2.3$ \\
B3 + FLZ & $9.12 \pm 2.0$ & $12.88 \pm 4.3$ & $55.32 \pm 5.2$ & $233.13 \pm 3.1$ \\
PTZ + FLZ + B3 & $4.33 \pm 1.8$ & $7.33 \pm 1.5$ & $85.20 \pm 1.3$ & $290.76 \pm 2.3$ \\
PTZ + FLZ + DZM & $10.33 \pm 3.8$ & $13.18 \pm 2.2$ & $65.05 \pm 4.4$ & $196.43 \pm 1.6^{* *}$ \\
\hline
\end{tabular}

Abbreviations: NS, normal saline; FLZ, flumazenil; DZM, diazepam; B3, 5-[(naphthalen-2-yloxy) methyl]-I,3,4-oxadiaszole2-thiol.



Figure 13 Representative Immuno-histochemical images of hematoxylin, eosin $(\mathrm{H}$ and $\mathrm{E})$ and quantified histogram of survival neuron reactivity and integrated density in cortex. 


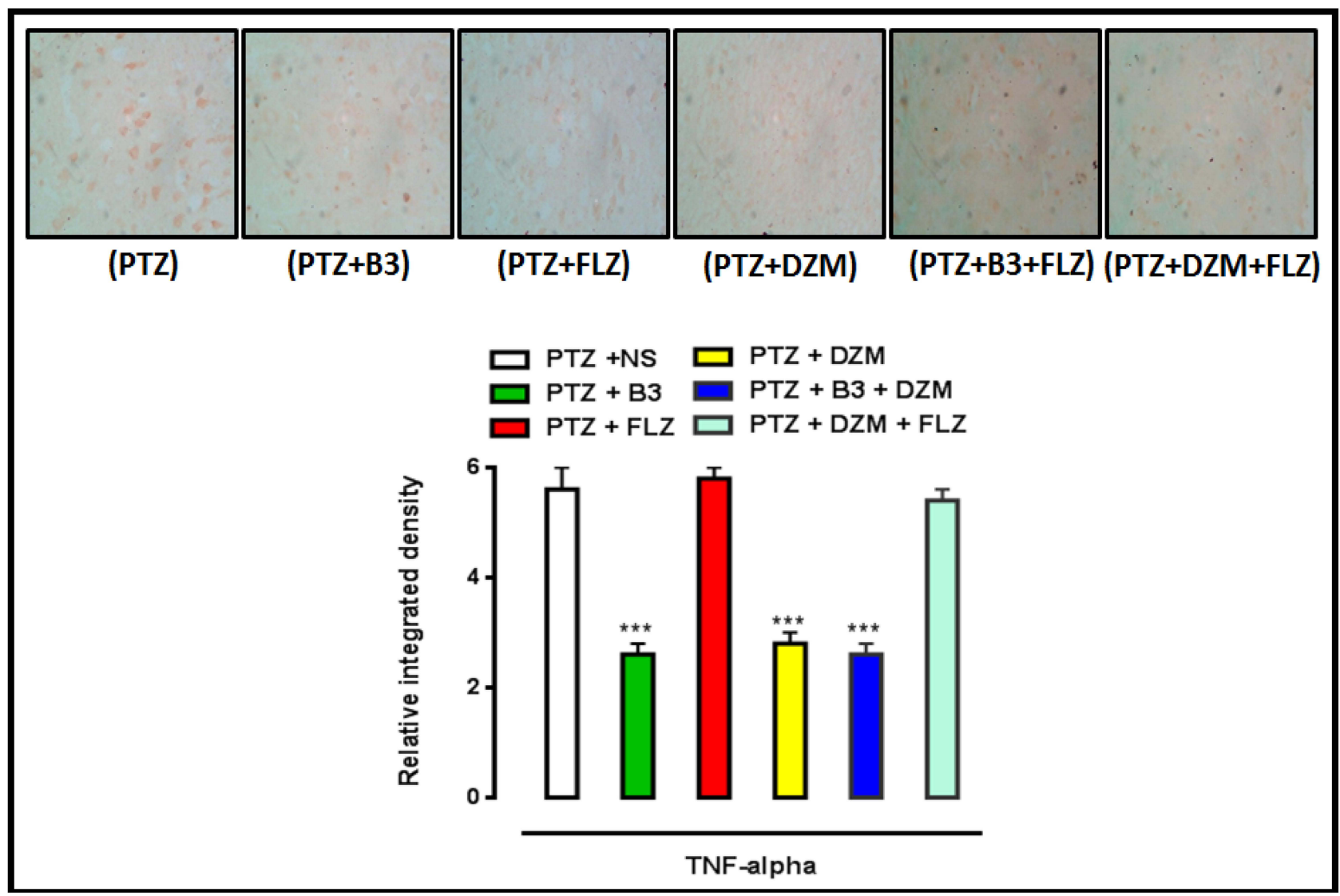

Figure 14 Immunohistochemical results of tumor necrosis factor (TNF)- $\alpha$ in the cortex of mice. Bar $20 \mu \mathrm{m}$, magnification $40 \times$. Histograms present a comparatively higher expression of TNF- $\alpha$ in the PTZ-induced seizure group ***P $<0.001$ present significant difference compared to the phenyltetrazole (PTZ)-group. Data are expressed as mean \pm standard error of mean (SEM) and analyzed by one-way analysis of variance (ANOVA), followed by post-hoc Tukey's test in Graph Pad Prism. The $P$ value was calculated using Graph Pad Instate.

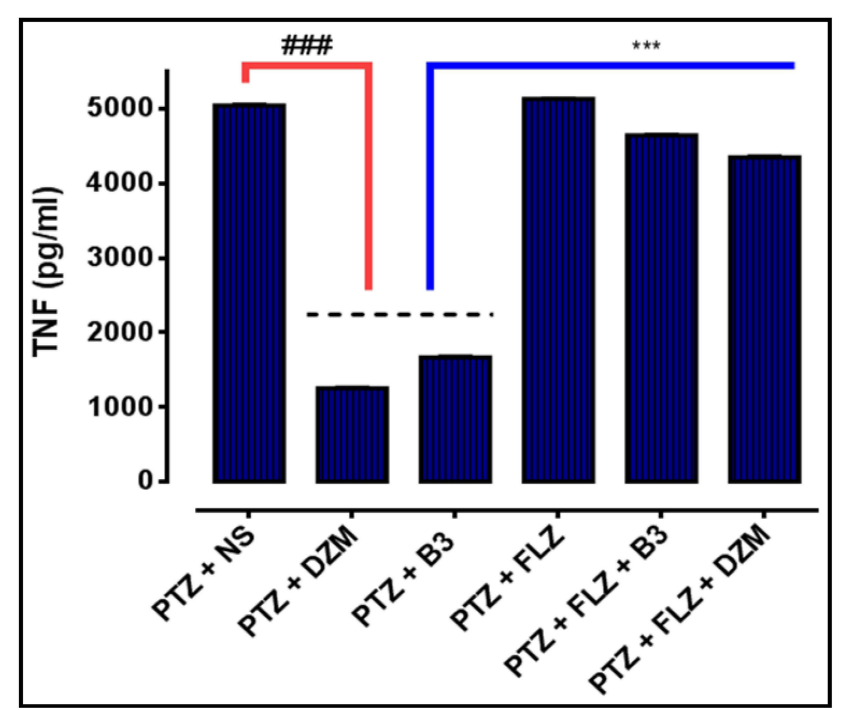

Figure 15 Protein expression of TNF- $\alpha$, quantified by using enzyme linked immunosorbent assay. (ELISA). The data are shown as mean \pm standard error of mean (SEM). ${ }^{* * *} \mathrm{P}<0.001$ indicates significant difference vs treatment group and ${ }^{\# \# P}$ $<0.00$ I shows significant difference vs PTZ. Data were analyzed by using one way analysis of variance (ANOVA), followed by post-hoc Tukey's test in Graph Pad Prism. The $P$ value was calculated using Graph Pad Instate. regulated the over expressed level of nitric oxide, lipid peroxidase and TNF- $\alpha$ which indicates the anti-neuro inflammatory potential.

\section{Conclusion}

The results revealed that $\mathrm{B} 3$ is a promising candidate possesses good binding affinity with GABA and form stable complex as confirmed by both molecular docking and molecular dynamic simulation studies. In addition to its role in correction of the behavioral deficits induced by PTZ, It increased the latency of seizures, elevated the level of GSH and GST, and meanwhile decreased the level of LPO and iNOS. It can reverse the PTZ induced pathological changes as established by $\mathrm{H} \& \mathrm{E}$ and IHC staining of brain. Therefore, the neuroprotective property of $\mathrm{B} 3$ may be arbitrated to the down regulation of TNF- $\alpha$, which is found to be up regulated in PTZ-induced seizures. Hence, the available results explain the potential of B3 for attenuating 
neurodegeneration and neuroinflammation caused by PTZ.

\section{Institutional Review Board Statement}

This work was approved by ethical committee of Riphah Institute of Pharmaceutical Sciences, Riphah International University, Islamabad.

\section{Data Sharing Statement}

All the data is incorporated in the manuscript.

\section{Acknowledgments}

All the authors are grateful to Riphah International University, Islamabad for providing lab space and chemicals to conduct experiments and smoothly finish this research work. Yusuf S. Althobaiti was supported by Taif University Researchers Supporting Project number (TURSP-2020/78), Taif University, Taif, Saudi Arabia.

\section{Author Contributions}

All authors made a significant contribution to the work presented in the manuscript including conception, study design, execution, acquisition of data, analysis and interpretation. Took part in drafting and critically reviewing the article, gave final approval of the version to be published, and agree to be accountable for all aspects of the work.

\section{Funding}

This research received no external funding.

\section{Disclosure}

The authors declare no conflicts of interest for this work.

\section{References}

1. Varvel NH, Jiang J, Dingledine R. Candidate drug targets for prevention or modification of epilepsy. Annu Rev Pharmacol Toxicol. 2015;55:229-247. doi:10.1146/annurev-pharmtox-010814-124607

2. Lees G, Leach MJ. Studies on the mechanism of action of the novel anticonvulsant lamotrigine (Lamictal) using primary neuroglial cultures from rat cortex. Brain Res. 1993;612(1):190-199. doi:10.1016/ 0006-8993(93)91660-K

3. Rosenow F, Strzelczyk A. Behavior. Individualized epilepsy management: medicines, surgery, and beyond. Epilepsy Behav. 2019;91:1-3. doi:10.1016/j.yebeh.2018.09.045

4. Rashidian A, Kazemi F, Mehrzadi S, et al. Anticonvulsant effects of aerial parts of Verbena officinalis extract in mice: involvement of benzodiazepine and opioid receptors. J Evid Based Complementary Altern Med. 2017;22(4):632-636. doi:10.1177/2156587217709930
5. Treiman DM. GABAergic mechanisms in epilepsy. Epilepsia. 2001;42:8-12.

6. Ochoa JG, Kilgo WA. The role of benzodiazepines in the treatment of epilepsy. Curr Treat Options Neurol. 2016;18(4):18. doi:10.1007/ s11940-016-0401-x

7. Shimada T, Yamagata KJJ. Pentylenetetrazole-induced kindling mouse model. J Vis Exp. 2018;136:e56573.

8. Hoffman E, Warren E. Flumazenil: a benzodiazepine antagonist. Clin Pharm. 1993;12(9):641-656; quiz 699-701.

9. Votey SR, Bosse GM, Bayer MJ, Hoffman JR. Flumazenil: a new benzodiazepine antagonist. Ann Emerg Med. 1991;20(2):181-188. doi:10.1016/S0196-0644(05)81219-3

10. Faheem M, Khan A-U, Nadeem H, Ali F. Computational and pharmacological evaluation of heterocyclic 1, 3, 4-oxadiazole and pyrazoles novel derivatives for toxicity assessment, tumour inhibition, antioxidant, analgesic and anti-inflammatory actions. Farmacia. 2018;66(5):909-919. doi:10.31925/farmacia.20 18.5.24

11. Faheem M, Ali SH, Khan AW, et al. 1, 3, 4-Oxadiazole derivative attenuates chronic constriction injury induced neuropathic pain: a computational, behavioral, and molecular approach. Brain Sci. 2020;10(10):731. doi:10.3390/brainsci10100731

12. Malghani Z, Khan A-U, Faheem M, et al. Molecular docking, antioxidant, anticancer and antileishmanial effects of newly synthesized quinoline derivatives. Anticancer Agents Med Chem. 2020;20 (13):1516-1529. doi:10.2174/1871520620666200516145117

13. Anwar T, Nadeem H, Sarwar S, et al. Investigation of antioxidant and anti-nociceptive potential of isoxazolone, pyrazolone derivatives, and their molecular docking studies. Drug Dev Res. 2020;81(7):893-903. doi:10.1002/ddr.21711

14. Ahmad S, Khan AU, Faheem M, et al. Computational and pharmacological evaluation of stevioside derivatives for antinociceptive and antiinflammatory potential. Trop $J$ Pharm Res. 2020;19 (8):1677-1684. doi:10.4314/tjpr.v19i8.16

15. Ivanova L, Tammiku-Taul J, García-Sosa AT, Sidorova Y, Saarma M, Karelson M. Molecular dynamics simulations of the interactions between glial cell line-derived neurotrophic factor family receptor GFR $\alpha 1$ and small-molecule ligands. ACS Omega. 2018;3(9):11407-11414. doi:10.1021/acsomega.8b01524

16. Hou H, Wang Y, Li C, Wang J, Cao Y. Dipeptidyl peptidase-4 is a target protein of epigallocatechin-3-gallate. Biomed Res Int. 2020;2020:54.

17. Eid EE, Azam F, Hassan M, Taban IM, Halim MA, Transduction S. Zerumbone binding to estrogen receptors: an in-silico investigation. J Recept Signal Transduct Res. 2018;38(4):342-351. doi:10.1080/ 10799893.2018.1531886

18. Khan AW, Khan AU, Ahmed T. Anticonvulsant, anxiolytic, and sedative activities of Verbena officinalis. Front Pharmacol. 2016;7:499. doi:10.3389/fphar.2016.00499

19. Nejad SR, Motevalian M, Fatemi I, Shojaii A. Anticonvulsant effects of the hydroalcoholic extract of Alpinia officinarum rhizomes in mice: involvement of benzodiazepine and opioid receptors. J Epilepsy Res. 2017;7(1):33. doi:10.14581/jer.17006

20. Hosseinzadeh H, Parvardeh S. Anticonvulsant effects of thymoquinone, the major constituent of Nigella sativa seeds, in mice. Phytomedicine. 2004;11(1):56-64. doi:10.1078/0944-711300376

21. Iqbal S, Shah FA, Naeem K, et al. Succinamide derivatives ameliorate neuroinflammation and oxidative stress in scopolamine-induced neurodegeneration. Biomolecules. 2020;10(3):443. doi:10.3390/ biom 10030443

22. Kumar KS, Hsieh HW, Wang S-Y. Anti-inflammatory effect of lucidone in mice via inhibition of NF-kB/MAP kinase pathway. Int Immunopharmacol. 2010;10(4):385-392. doi:10.1016/j.intimp.20 09.12.013 
23. Imran M, Al Kury LT, Nadeem H, et al. Benzimidazole containing acetamide derivatives attenuate neuroinflammation and oxidative stress in ethanol-induced neurodegeneration. Biomolecules. 2020;10 (1):108. doi:10.3390/biom 10010108

24. Al Kury LT, Zeb A, Abidin ZU, et al. Neuroprotective effects of melatonin and celecoxib against ethanol-induced neurodegeneration: a computational and pharmacological approach. Drug Des DevelTher. 2019;13:2715.

25. Mohsin Alvi A, Tariq Al Kury L, Umar Ijaz M, et al. Post-treatment of synthetic polyphenolic 1, 3, 4 oxadiazole compound A3, attenuated ischemic stroke-induced neuroinflammation and neurodegeneration. Biomolecules. 2020;10(6):816. doi:10.3390/biom10060816

26. Ali A, Shah FA, Zeb A, et al. NF-kB inhibitors attenuate MCAO induced neurodegeneration and oxidative stress-a reprofiling approach. Front Mol Neurosci. 2020;13:33. doi:10.3389/fnmol.2020.00033

27. Komirishetty P, Areti A, Gogoi R, Sistla R, Kumar A. Combination strategy of PARP inhibitor with antioxidant prevent bioenergetic deficits and inflammatory changes in CCI-induced neuropathy. Neuropharmacology. 2017;113:137-147. doi:10.1016/j.neuropharm. 2016.09.027

28. Van Erum J, Van Dam D, De Deyn PP. PTZ-induced seizures in mice require a revised Racine scale. Epilepsy Behav. 2019;95:51-55. doi:10.1016/j.yebeh.2019.02.029

29. Viswanatha GL, Shylaja H, Kishore DV, Venkataranganna MV, Prasad NBL. Acteoside isolated from colebrookea oppositifolia smith attenuates epilepsy in mice via modulation of gamma-aminobutyric acid pathways. Neurotox Res. 2020;38 (4):1010-1023. doi:10.1007/s12640-020-00267-0

30. Alvi AM, Al Kury LT, Alattar A, et al. Carveol attenuates seizure severity and neuroinflammation in pentylenetetrazole-kindled epileptic rats by regulating the Nrf2 signaling pathway. Oxid Med Cell Longev. 2021;2021:452.

31. Cramer JA, Mintzer S, Wheless J, Mattson RH. Adverse effects of antiepileptic drugs: a brief overview of important issues. Expert Rev Neurother. 2010;10(6):885-891. doi:10.1586/ern.10.71

32. Sahu M, Siddiqui N, Naim MJ, et al. Design, synthesis, and docking study of pyrimidine-triazine hybrids for GABA estimation in animal epilepsy models. Arch Pharm. 2017;350(9):1700146. doi:10.1002/ ardp. 201700146

33. Fabjan J, Koniuszewski F, Schaar B, Ernst M. Structure-guided computational methods predict multiple distinct binding modes for pyrazoloquinolinones in GABAA receptors. Front Neurosci. 2021;14:1452. doi:10.3389/fnins.2020.611953

34. Hollingsworth SA, Dror RO. Molecular dynamics simulation for all. Neuron. 2018;99(6):1129-1143. doi:10.1016/j.neuron.2018.08.011

35. Karplus M, McCammon JA. Molecular dynamics simulations of biomolecules. Nat Struct Biol. 2002;9(9):646-652. doi:10.1038/ nsb0902-646

36. McCammon JA, Gelin BR, Karplus M. Dynamics of folded proteins. Nature. 1977;267(5612):585-590. doi:10.1038/267585a0

37. Levitt M, Lifson S. Refinement of protein conformations using a macromolecular energy minimization procedure. $J$ Mol Biol. 1969;46(2):269-279. doi:10.1016/0022-2836(69)90421-5

38. Dawe GB, Musgaard M, Aurousseau MR, et al. Distinct structural pathways coordinate the activation of AMPA receptor-auxiliary subunit complexes. Neuron. 2016;89(6):1264-1276. doi:10.1016/j. neuron.2016.01.038

39. McCorvy JD, Butler KV, Kelly B, et al. Structure-inspired design of $\beta$-arrestin-biased ligands for aminergic GPCRs. Nat Chem Biol. 2018;14(2):126-134. doi:10.1038/nchembio.2527

40. Spahn V, Del Vecchio G, Labuz D, et al. A nontoxic pain killer designed by modeling of pathological receptor conformations. Science. 2017;355(6328):966-969. doi:10.1126/science.aai8636
41. Chinnala KM, Shanmugam D, Elsani MM. Antiepileptic activity of Alstonia scholaris Linn. on Mes, Ptz and Strychnine induced convulsions in rats. Int $j$ Pharm Biol Sci. 2016;6(1):207-213.

42. El-Missiry MA, Othman AI, Amer MA, Sedki M, Ali SM, ElSherbiny IM. Nanoformulated ellagic acid ameliorates pentylenetetrazol-induced experimental epileptic seizures by modulating oxidative stress, inflammatory cytokines and apoptosis in the brains of male mice. Metab Brain Dis. 2020;35(2):385-399. doi:10.1007/s11011-019-00502-4

43. Temp FR, Marafiga JR, Milanesi LH, et al. Cyclooxygenase-2 inhibitors differentially attenuate pentylenetetrazol-induced seizures and increase of pro-and anti-inflammatory cytokine levels in the cerebral cortex and hippocampus of mice. Eur J Pharmacol. 2017;810:15-25. doi:10.1016/j.ejphar.2017.05.013

44. Yuhas Y, Shulman L, Weizman A, et al. Involvement of tumor necrosis factor alpha and interleukin-1 $\beta$ in enhancement of pentylenetetrazoleinduced seizures caused by Shigella dysenteriae. Infect Immun. 1999;67 (3):1455-1460. doi:10.1128/IAI.67.3.1455-1460.1999

45. Vitaliti G, Pavone P, Marino S, Saporito MAN, Corsello G, Falsaperla R. Molecular mechanism involved in the pathogenesis of early-onset epileptic encephalopathy. Front Mol Neurosci. 2019;12:118. doi:10.3389/fnmol.2019.00118

46. Chao CC, Hu SX, Ehrlich L, Peterson PK. Interleukin-1 and tumor necrosis factor- $\alpha$ synergistically mediate neurotoxicity: involvement of nitric oxide and of N-methyl-D-aspartate receptors. Brain Behav Immun. 1995;9(4):355-365. doi:10.1006/brbi.1995.1033

47. Patel DC, Wallis G, Dahle EJ, et al. Hippocampal TNF $\alpha$ signaling contributes to seizure generation in an infection-induced mouse model of limbic epilepsy. eNeuro. 2017;4(2):ENEURO.010517.2017. doi:10.1523/ENEURO.0105-17.2017

48. Akiyama $\mathrm{H}$, Barger $\mathrm{S}$, Barnum $\mathrm{S}$, et al. Inflammation and Alzheimer's disease. Neurobiol Aging. 2000;21(3):383-421. doi:10.1016/S0197-4580(00)00124-X

49. Eikelenboom P, Bate C, Van Gool W, et al. Neuroinflammation in Alzheimer's disease and prion disease. Glia. 2002;40(2):232-239. doi:10.1002/glia.10146

50. Mu Y, Gage FH. Adult hippocampal neurogenesis and its role in Alzheimer's disease. Mol Neurodegener. 2011;6(1):1-9. doi:10.1186/ 1750-1326-6-85

51. Pascual M, Blanco AM, Cauli O, Miñarro J, Guerri C. Intermittent ethanol exposure induces inflammatory brain damage and causes long-term behavioural alterations in adolescent rats. Eur $J$ Neurosci. 2007;25(2):541-550. doi:10.1111/j.1460-9568.2006.05298.x

52. Zhang J, Li J-C, Song J-L, Cheng Z-Q, Sun J-Z, Jiang C-S. Synthesis and evaluation of coumarin/1, 2, 4-oxadiazole hybrids as selective BChE inhibitors with neuroprotective activity. J Asian Nat Prod Res. 2018;21(11):1090-1103. doi:10.1080/10286020.2018.1492566

53. Biernacki K, Daśko M, Ciupak O, Kubiński K, Rachon J, Demkowicz S. Novel 1, 2, 4-oxadiazole derivatives in drug discovery. Pharmaceuticals. 2020;13(6):111. doi:10.3390/ph13060111

54. Mohammadi-Khanaposhtani M, Saeedi M, Zafarghandi NS, et al. Potent acetylcholinesterase inhibitors: design, synthesis, biological evaluation, and docking study of acridone linked to 1, 2, 3-triazole derivatives. Eur J Med Chem. 2015;92:799-806. doi:10.1016/j.ejmech.2015.01.044

55. Mohammadi-Khanaposhtani M, Shabani M, Faizi M, et al. Design, synthesis, pharmacological evaluation, and docking study of new acridone-based 1, 2, 4-oxadiazoles as potential anticonvulsant agents. Eur J Med Chem. 2016;112:91-98. doi:10.1016/j.ejmech.2016.01.054 


\section{Publish your work in this journal}

The Journal of Inflammation Research is an international, peerreviewed open-access journal that welcomes laboratory and clinical findings on the molecular basis, cell biology and pharmacology of inflammation including original research, reviews, symposium reports, hypothesis formation and commentaries on: acute/chronic inflammation; mediators of inflammation; cellular processes; molecular mechanisms; pharmacology and novel anti-inflammatory drugs; clinical conditions involving inflammation. The manuscript management system is completely online and includes a very quick and fair peerreview system. Visit http://www.dovepress.com/testimonials.php to read real quotes from published authors. 